NBER WORKING PAPER SERIES

\title{
THE EFFECTS OF PROVIDER CHOICE POLICIES ON WORKERS' COMPENSATION COSTS
}

\author{
David Neumark \\ Bogdan Savych \\ Working Paper 23611 \\ http://www.nber.org/papers/w23611 \\ NATIONAL BUREAU OF ECONOMIC RESEARCH \\ 1050 Massachusetts Avenue \\ Cambridge, MA 02138 \\ July 2017
}

We are grateful to Peter Barth, Richard Butler, Jim Dertouzos, John Ruser, Carol Telles, Rick Victor, and many workers' compensation practitioners for helpful comments. Any errors or omissions remaining in this paper are the responsibility of the authors. The views expressed are those of the authors, and not the Workers Compensation Research Institute (WCRI). The views expressed herein are those of the authors and do not necessarily reflect the views of the National Bureau of Economic Research.

NBER working papers are circulated for discussion and comment purposes. They have not been peer-reviewed or been subject to the review by the NBER Board of Directors that accompanies official NBER publications.

(C) 2017 by David Neumark and Bogdan Savych. All rights reserved. Short sections of text, not to exceed two paragraphs, may be quoted without explicit permission provided that full credit, including (๑) notice, is given to the source. 
The Effects of Provider Choice Policies on Workers' Compensation Costs

David Neumark and Bogdan Savych

NBER Working Paper No. 23611

July 2017

JEL No. H7,I18

\begin{abstract}
We examine the effects of provider choice policies on workers' compensation medical and indemnity costs. We find no difference in average medical costs between states where policies give employers control over the choice of provider and states where policies instead give workers the most control. But a richer distributional analysis indicates that developed medical costs for the costliest cases are higher in states where policies give workers more control over provider choice. We find similar evidence for indemnity costs, although the point estimates also indicate (statistically insignificantly) higher average costs where policy gives workers the most control over provider choice. Overall, the evidence suggests little relationship between provider choice policies and average medical or indemnity costs, but a higher incidence of high-cost cases when policies give workers more control of the choice of provider.
\end{abstract}

\author{
David Neumark \\ Department of Economics \\ University of California at Irvine \\ 3151 Social Science Plaza \\ Irvine, CA 92697 \\ and NBER \\ dneumark@uci.edu \\ Bogdan Savych \\ Workers Compensation Research Institute \\ 955 Massachusetts Ave. \\ Cambridge, MA \\ 02139 \\ bsavych@gmail.com
}




\section{Introduction}

Workers and their advocates have argued that provider choice in workers' compensation cases should be left to the worker, or at a minimum that workers should be treated by those they trust, and whose interests in prompt return to work as medically indicated, and the fullest restoration possible of physical capacity, are aligned with the worker's interest (Ellenberger, 1992). In contrast, employer advocates argue that employer choice is necessary because without it there is "...little incentive to see that the costs of care remain reasonable and appropriate..." (Morrison, 1990), and because employer choice "serves to direct injured workers away from those providers who provide excessive services and treatment procedures" and to "retain those providers familiar with the operations of the employer and who can expedite return to work based on that knowledge" (National Federation of Independent Business Research Foundation and National Foundation for Unemployment Compensation and Workers' Compensation, n.d.).

Earlier research on this topic suggested that policies that give employers more control over the choice of provider are associated with lower medical payments (Victor and Fleischman, 1990; Durbin and Appel, 1991; Washington Department of Labor and Industries and University of Washington Department of Health Services, 1997), although some studies found essentially no effect (Boden and Fleischman, 1989; Boden, 1992) or even the opposite (Pozzebon, 1994). More recently, Neumark et al. (2007) studied medical costs along with other outcomes. They used information on who chose the provider rather than the policy per se; the latter influences but does not fully determine who chooses the provider. Looking at the simple dichotomy of employee versus employer choice of the provider, they found that costs were generally higher and return-to-work outcomes worse when workers selected the provider, despite workers reporting similar recovery of physical health and higher satisfaction with overall care. ${ }^{1,2}$

\footnotetext{
${ }^{1}$ However, the adverse cost and return-to-work outcomes were largely associated with employee choice of new providers, rather than employee choice of providers with whom they had a prior relationship, suggesting that policymakers might be able to find a middle ground that moderates costs without sacrificing recovery of physical health by allowing workers to continue to be treated by providers with whom they have a pre-existing relationship, but otherwise allowing the employer to select providers.

${ }^{2}$ Recently, Shraim et al. (2015) found lower medical costs for low back pain cases in states where employers have more control over the initial provider choice, but higher medical costs in states that limit subsequent provider change relative to states that allow a one-time provider change. These conclusions contrast with ours, and for several reasons we regard our estimates as more informative about the effects of provider choice policies on workers' compensation costs. In Appendix A (on-line), we provide comparisons between our study and theirs, and discuss how to interpret the evidence from the two studies and why we think our estimates are most informative.
} 
The jumping off point for this study is the difference between who actually chose the provider, which Neumark et al. (2007) studied, and provider choice policy. The data used in the 2007 study covered only four states, making it impossible to draw any firm conclusions about the relationships between states' provider choice policies and outcomes. In contrast, the data we use in the present study cover 25 states. We use claims data, which allow us to study medical and indemnity costs.

Evidence on the effects of provider choice policies is critical for two reasons. First, because policy influences but by no means determines who chooses the provider, who actually ends up choosing the provider can be selective, based on the nature of the injury and other factors. This selective determination of the choice of provider implies that the estimated relationships between workers' compensation costs and who actually chose the provider can be uninformative about the impact of policies. For example, workers with more complicated or expensive cases may end up choosing their providers because of contested issues or medical complications, in which case evidence of higher costs when workers choose the provider would overstate the effect on costs of policies allowing them to choose their own providers. Second, the statutes governing provider choice are what is most directly subject to influence by policymakers.

\section{Provider Choice Policy}

Policies or regulations determining who controls provider choice vary along two key dimensions: who controls the initial choice of the primary treating provider, ${ }^{3}$ and the ability of workers and employers to change the primary treating provider. Because the treating provider shapes the treatment approach, and determines whether the worker is fit to go back to work, work restrictions, and remaining impairment, the treating provider can influence costs and other outcomes. We therefore characterize policies in terms of workers' and employers' ability to choose the treating provider. ${ }^{4}$

Table 1 shows that, for the period covered by our data (injury years 2007-2010), we can, broadly speaking, classify states as to whether the employer (e.g., Alabama) or the employee (e.g., Arizona)

\footnotetext{
${ }^{3}$ We use the term treating provider to refer to the main medical provider responsible for making decisions about the nature of care that workers received and for releasing workers back to work. State regulations often specify that treating providers be physicians (including surgeons), although they may also be chiropractors.

${ }^{4}$ However, evidence that provider choice policies do not determine but only influence the choice of provider highlights the point that there can be differences between what workers' compensation statutes say and how policies are in fact implemented.
} 
controls the initial choice of provider. Both categories, however, include policy variation, some of which may have a substantial impact on the choice of the provider who is more responsible for directing the patient's care. These variations are also described in Table 1.

The first variation has to do with the ability of employers to restrict the list of providers from which workers can initially choose. For example, provider choice policies in Georgia, Tennessee, and Virginia limit workers' choices to a list of providers selected by their employers, potentially giving employers a great deal of control over provider choice, even though workers might appear to be able to choose their treating providers. ${ }^{5}$ The limitation may also depend on whether employers select a panel; if employers fail to select providers for the panel, workers may have more choice of providers. In some other states, when employers have a contract with a managed care organization (MCO), the choice of provider can be limited to the providers within the network. In these states (such as California, Kentucky, Minnesota, and Texas), workers likely have more choice than when employers can simply specify the list of providers, although that would depend on the size of the network. It is also the case that in some states, if the employer does not have a managed care plan, then workers can choose their providers. We do not know in our data whether employers have such plans and, hence, we exclude from our analysis the small number of states where the choice of provider is primarily from a network.

The second potentially important variation is the ability of workers or employers to change providers after the initial choice is exercised, which can also influence who ultimately chooses the primary treating provider. ${ }^{6}$ In some states, workers are allowed to change their providers quite freely, whether the worker controls the initial choice (e.g., Maryland), the worker chooses from a limited panel of providers (e.g., Pennsylvania), or the employer chooses (e.g., Michigan). In other states, in contrast, the number of changes may be limited (such as Florida and Wisconsin), or changing the provider may be limited by

\footnotetext{
${ }^{5}$ When the list of providers from which workers choose is small, workers' ability to choose might in fact be limited. The extent to which this choice is limited may depend on the number of providers in an area. In rural areas, the panel may include all of the providers that are available in the area, although the regulations sometimes allow drawing doctors from a wide geographic area, which may reduce this concern.

${ }^{6}$ We do not know how frequently the ability to restrict changes in providers is exercised. But the possibility of being able to restrict such changes could, in principle, create incentives for providers to provide efficient care (from the perspective of the employer), lest they become subject to restrictions on workers' ability to switch to them.
} 
allowing workers to change providers only with the agreement/approval of the employer (such as in Indiana, North Carolina, and Virginia).

Note that policies regarding workers' ability to change providers can sometimes simply make worker choice, in a sense, even more flexible than it already is - most starkly in Maryland, where workers control the initial choice of provider and have unrestricted ability to change providers. In this kind of case, we would not expect the difference with regard to the ability to switch providers to influence worker control of the choice of primary provider. ${ }^{7}$ In other cases, however, the ability of workers to change providers might be expected to undermine - perhaps substantially—policies that give employers the right to choose the initial provider. Most notable is Michigan, where the employer controls the choice of initial provider for a short period of time after an injury—10 days—-but workers can change providers an unlimited number of times after the period of employer control is over. But even the ability of workers to change providers a limited number of times - for example, in Florida, where workers can request that employers choose another provider that is not affiliated with their current provider — can undermine employer control of the choice of the initial provider.

Bringing together the two types of variation in provider choice policies emphasized in Table 1, the ability of workers to change providers can give the worker more scope to choose the primary provider in states that dictate employer choice from a panel or from a network. However, this ability may not grant much flexibility. For example, for 90 days after an injury, workers in Pennsylvania can change providers only within the panel but after that can choose other providers.

Based on these variations in provider choice policies, states can be grouped based on the degree to which employers or workers control the choice of provider. As a result, we consider the following grouping of states, which can plausibly be thought of as two polar classifications by the degree to which the worker controls the initial choice of provider (see Table 2):

\footnotetext{
7 There are no states in Table 1 in which the employer has the ability to change providers after the worker initially has chosen a treating provider. Thus, the ability of employers to change providers is only relevant in states in which the employer already controls the initial choice of provider (like in Indiana and North Carolina). Like with the case of states where the worker chooses the initial provider and the worker can change providers, we would not expect the difference with regard to the ability of employers to switch providers to influence employer control of the choice of primary provider; hence, we pay no further attention to whether employers can change providers.
} 
- States with employer choice of provider or control of a panel of providers, with very restricted option for worker to change provider.

- States with worker choice or where workers have considerable ability to change providers.

Although this classification combines elements of choice of initial provider and the ability to change provider, it has the virtue of providing a parsimonious division of states, likely affording more reliable estimation of the differences in costs associated with different provider choice policies. Some states are unambiguously in one group. For other states, we had to make decisions about the classification. ${ }^{8,9}$

Our classification of states inevitably ignores some detail. Even with 25 states available to study, we have to impose some restrictions to categorize groups of states in terms of policy rather than just treating each state as idiosyncratic. We do believe that we have focused on the main dimensions of provider choice policies.

Table 1 does not report changes over time in provider choice policies, because these policies have not changed over the 2007-2010 time period (injury years) covered by our data. Many changes to provider choice laws occurred much earlier in the 1980s and 1990s — a period of rising workers' compensation costs (Victor et al., 2005)—when states implemented rules that required workers to select providers from within approved networks of providers that were established by employers. There have also been some recent changes to provider choice policies over the last decade, including California in 2005 and Texas in $2006 .{ }^{10}$ Our data do not cover these policy changes in California and Texas. However, these reforms may have

\footnotetext{
${ }^{8}$ It should be obvious from Table 1 how most states get classified in Table 2. Note that one of the states in the second group (Michigan) is a state where the employer controls the choice of the initial provider directly, but 10 days after an injury the worker has unrestricted choice. Effective December 19, 2011, Michigan Public Act 266 extended employer control of providers from 10 to 28 days.

${ }^{9}$ Our classification of states is based on policy, not how choice of either the initial or primary provider is actually exercised. Evidence based on survey information from a limited number of states shows that state policy influences but does not determine who chooses the primary provider, either because workers or employers may let the other party choose even when they have the right to choose, or because employers may not take advantage of some policy provisions. As an example of the latter case, if employers have the right to restrict workers to providers in a network but do not set up a network, then workers can choose their providers in an unrestricted fashion.

${ }^{10}$ In California, prior to 2005, employers had the right to select the initial provider unless the employee had predesignated a provider; after 30 days, the worker could change to a medical provider of his or her own choice. Subsequent changes allowed employers to establish medical treatment networks, and workers could select providers from the network; all future provider changes and referrals must occur within that same network. In Texas, effective January 2006, if the insurer has contracted with a medical network, the injured employee could initially choose a treating provider from the network list. Prior to the reforms, workers were choosing providers from the list of providers from the Commission's Approved Doctor List (ADL).
} 
been a response to high costs, an issue we address below.

\section{Data}

\section{Workers' compensation claims}

Data on workers' compensation claims come from the Workers Compensation Research Institute (WCRI) Detailed Benchmark/Evaluation (DBE) database, which contains over 41 million workers' compensation claims with data from a majority of states. These data come from claims payors - insurers, state funds, and self-insured employers. We extracted information about the worker, employer, injury, and costs of each case in the study from the WCRI DBE database. We use measures of both indemnity benefits and medical payments per claim, which in the WCRI DBE database are standardized across payors and states.

We focus on workers' compensation claims for injuries between October 2006 and September 2010 with an average of 36 months' maturity. ${ }^{11}$ Our analysis sample includes over 4,000,000 claims.

The outcomes we study include incurred medical and indemnity costs and developed medical and indemnity costs. Incurred costs include anything that was paid out plus reserves that are allocated to the claim, so they reflect what was actually paid out within an average 36 months of maturity plus expert judgment from adjustors on each specific claim. Developed costs add additional actuarial modeling and are, in principle, the best measure of ultimate costs, although they can reflect some unknowns. We believe that, in principle, developed costs are the most meaningful from a policy perspective, but the potential inaccuracy relative to actual "final" costs also means that they are not definitive, which is why we also present evidence on incurred costs.

We project ultimate developed costs for each claim based on development factors provided by NCCI (2014, exhibit 9). Conceptually, development factors reveal how average indemnity and medical costs per claim are expected to change when more claim experience is accumulated. They can be used to project the ultimate average claim costs given only a few years of post-injury cost experience. Since the

\footnotetext{
${ }^{11}$ In the DBE, injury year 2007, for example, is defined as claims arising from October 1, 2006, through September 30, 2007. For these 2007 claims, we collected information about experience through March 31, 2010 - so we examine 2007 claims with an average maturity of 36 months. Injures in other years are evaluated similarly.
} 
data underlying this analysis reflect individual claims, we use development factors as the guide to how much claim costs may change beyond our window of an average 36 months of post-injury experience. In particular, we apply aggregate development factors to project ultimate claim costs. ${ }^{12}$

\section{Other workers' compensation policies}

Because state workers' compensation systems differ along many dimensions, we also control for features of these systems that might affect costs, so that we do not mistakenly attribute to provider choice policies the effects of other policies. And as noted earlier, provider choice policies do not vary within states over the range of years covered in our analysis, so we cannot include state fixed effects to control for other (fixed) dimensions of state workers' compensation policies. ${ }^{13}$ Given that we focus on both medical costs and indemnity costs, it is presumably most important to control for other policies that are likely to be related to these two cost dimensions. Our policy controls, by state, are listed in Table 3.

One policy dimension we want to capture is the generosity of workers' compensation temporary disability benefits_-income replacement benefits paid to workers while they are recovering after injuries, which can influence incentives to return to work. There are numerous ways to capture this generosity. One, of course, pertains to the weekly benefits that workers receive. These are typically determined as workers' preinjury average weekly wages multiplied by the statutory replacement rate, subject to maximum and minimum amounts. ${ }^{14}$ To capture benefit generosity in a parsimonious manner, we use the individual replacement rate. This measure is related to other measures of benefit generosity. For example, New Jersey had the highest average replacement rate (70 percent), reflecting a higher statutory replacement rate (70

\footnotetext{
${ }^{12}$ Before we can apply NCCI's development factors (we use five-year cumulative development factors for both indemnity and medical costs measures reported in NCCI, 2014) to project ultimate claim costs, we need to adjust for a number of definitional differences between NCCI's and WCRI's measures. These, and other issues in projecting developed costs, including evidence that our results are robust to different assumptions used in estimated developed costs - as well as other analyses of the robustness of the results to differences in the specification or estimation-are described in Neumark and Savych (2017).

${ }^{13}$ Of course, given that the other policies we include do vary over time within states in our sample, we would want to include these even if we could include fixed state effects.

${ }^{14}$ Maximum benefit amounts are commonly determined by applying the statutory maximum benefit rate-which can be below or above 100 percent, although it is commonly set at 100 - to the statewide average weekly wage (SAWW) estimated with a lag of one or two years. For some workers, the maximum rates are binding, in which case the effective replacement rate for them is lower than for many other workers. The minimum rates can also be binding.
} 
percent of SAWW). ${ }^{15}$

Relative generosity of benefits may also be related to whether states use a wage-loss or impairment approach to compensate for permanently disabling injuries, which may determine the flow of income benefits and influence patterns of medical care. Under a wage-loss system, workers receive payments for permanently disabling injuries based on the actual wage losses that persist after an injury, while an impairment system compensates permanently disabling injuries based on an impairment rating (see, Barth and Niss [1999] and Welch [2008]). ${ }^{16}$ We capture states that use a wage-loss approach-our second measure of state workers' compensation policies—-with a dummy variable. ${ }^{17}$

Many policies can affect medical prices and medical care utilization. Medical fee schedule rates have a direct effect on the prices of medical services and may determine doctors' willingness to provide medical care to patients with workers' compensation claims. ${ }^{18} \mathrm{We}$ control for the fee schedule as a percent of Medicare rates, to capture interstate variation in medical prices relative to the state's Medicare rates for office visits and surgeries. We also include an indicator variable for whether the state regulates payments to medical providers using a fee schedule, and an indicator for whether the state mandates the use of treatment guidelines or requires utilization review, which can influence which medical services are authorized and provided and hence costs.

\footnotetext{
${ }^{15} \mathrm{We}$ verified that the replacement rate is positively correlated with maximum benefits as a percentage of the SAWW (correlation coefficient 0.049 ), negatively correlated with the percentage of workers receiving the maximum benefit (correlation coefficient -0.406 ), and positively correlated with the percentage of workers receiving the minimum benefit (correlation coefficient 0.350 ), as we would expect.

${ }^{16}$ Barth and Niss (1999) and Welch (2008) identify several other approaches for reimbursing permanently disabling injuries, including loss of wage-earnings capacity systems or bifurcated systems that include components of multiple approaches. We do not use a more detailed classification of the approaches toward permanent partial disability (PPD) benefits since our main outcomes of interest are total indemnity payments or total medical payments and not PPD benefits. Furthermore, we are constrained in the number of policy variables that we can include since more detailed controls for other workers' compensation policies may mean that we end up identifying the effects of provider choice policies from a smaller number of states.

${ }^{17}$ The states that have components of both impairment and wage-loss systems (North Carolina and Georgia) were classified as wage-loss states. For more details on system features in those states, see Telles (2016) and Yang (2016). Another dimension of benefit generosity is limits on the duration of benefits. Some states impose limits on the duration of temporary total disability (TTD) benefits (with limits ranging from 104 to 500 weeks); other states may impose limits on duration of permanent disability benefits. The incentive effects of these measures on worker outcomes are likely to be indirect. First, few workers in our sample received temporary disability benefits near the threshold of limits, although that threshold may still affect settlement behavior. And second, even when TTD benefits are exhausted, workers who still have permanent impairment may receive PPD benefits.

${ }^{18}$ More details about workers' compensation fee schedules and relevant policy issues are provided in Fomenko and Liu (2012) and Fomenko and Victor (2013).
} 
We also need to account for differences across states in other workers' compensation policy features that can affect costs, in particular waiting periods (the number of days that workers have to be off work before qualifying for income replacement benefits) and retroactive periods (the number of days that workers have to wait before they qualify to receive income payments for the time off during the waiting period). The waiting periods in the states included in this study vary between three and seven days. Second, we need to account for differences in regulations about the number of days that workers have to wait before they qualify to receive income payments for the time off during the waiting period $-\mathrm{a}$ "retroactive period." ${ }^{19}$ We use linear controls for both of these.

The workers' compensation policies we include as controls do not exhaustively cover all differences in such policies across states. Given the limited number of states, we had to adopt a parsimonious set of controls for other workers' compensation policies. We selected those that were most likely to be significant determinants of the medical and indemnity costs we study and, hence, those for which it is most important to control in order to isolate the effects of provider choice policies on costs. ${ }^{20}$

\section{Other controls}

Characteristics of workers and employers can also affect workers' compensation costs, so we want to control for these in case there are compositional differences across states. The worker controls we include — based on what is available in the DBE database — are age, gender, marital status, job tenure at the time of injury, and wages. Workplace characteristics include firm size and a breakdown of industries and occupations based on injury risk. ${ }^{21}$ Characteristics of the local labor market may also affect return to work and, hence, indemnity costs, so we control for the county unemployment rate and residence in a micropolitan or metropolitan area.

We would also expect medical and indemnity costs to depend on the characteristics of the injury.

\footnotetext{
${ }^{19}$ For instance, when a state has a waiting period of 7 days and a retroactive period of 14 days, it means that workers will be paid income benefits for the first 7 days off work only if the duration of disability lasts more than 14 days. In this case, workers who spend a total of 13 days off work will receive income payments for 6 days off work, while workers who spend 15 days off work will receive payments for the full 15 days off work, leading to differences in the average indemnity payments across states with different retroactive periods.

${ }^{20}$ Since the application of specific workers' compensation policy rules may be subject to interpretation, we informally confirmed with state experts that our categorization of the policies reflects their experience with the system.

${ }^{21}$ This includes high-risk services, low-risk services, clerical/professional occupations (regardless of industry), manufacturing, construction, trade, and other industries; see Yang (2013, Technical Appendix).
} 
We therefore include indicator variables for injury type, based on the diagnostic (International Classification of Diseases, 9th Revision [ICD-9]) codes assigned by the providers, including neurologic spine pain (e.g., discs, peripheral neuropathy); back and neck sprains, strains and non-specific pain; fractures; lacerations and contusions; inflammations; other (non-back) sprains and strains; upper extremity neurologic pain (carpal tunnel); and a residual category of other injuries. ${ }^{22}$

Other variables that may be informative about injury severity — such as whether there was an overnight hospitalization, and whether the treatment included major surgery — are potentially problematic because they can also in turn be affected by who chose the provider, which is in turn influenced by policy. The potential risk then is that these types of variables could "over-control" for injury severity, capturing not only remaining variation in severity but also outcomes of provider choice policies that are more appropriately thought of as effects of these policies. For this reason, we exclude these kinds of controls.

\section{Empirical Methods}

For both medical and indemnity costs, we estimate linear models for a continuous outcome $\mathrm{Y}_{\text {ist }}$, where ' $\mathrm{i}$ ' indexes individuals, ' $\mathrm{s}$ ' indexes states, and ' $\mathrm{t}$ ' indexes injury year, of the form:

$$
\mathrm{Y}_{\text {ist }}=\alpha+\mathrm{PCP}_{\mathrm{is}} \beta+\mathrm{POL}_{\mathrm{ist}} \gamma+\mathrm{X}_{\mathrm{is} \delta} \delta+\mathrm{D}_{\mathrm{t}} \lambda+\varepsilon_{\mathrm{ist}}
$$

PCP captures provider choice policies. Given that we study states classified in one of two ways, we treat states where policy gives employers control over the choice of provider as the reference category, and include a dummy variable for states where policy gives workers controls, as classified in Table 2. POL is a vector of other workers' compensation policies (Table 3). X includes the worker, employer, and injury characteristics. $D_{t}$ is a vector of injury year dummy variables; these control for changes over time in workers' compensation costs that are common across states. Because there is no within-state variation in the provider choice policies (PCP), we cannot include state dummy variables and still identify the effects of these policies; hence, the equation does not include fixed state effects, and PCP does not have a t subscript.

\footnotetext{
${ }^{22}$ In some cases, workers may be assigned multiple diagnosis codes during the course of their disability. We define a primary diagnosis code based on the code that receives the greatest expenditure. Also, in some cases diagnosis codes are missing in the database, in which case we use information from the payor about the nature of injury and part of body to assign the appropriate injury group.
} 
Because provider choice policies vary at the state level, all standard errors used in our significance tests are clustered at the state level.

Much of our analysis of medical costs and indemnity costs is based on standard ordinary least squares (OLS) linear regressions, with Y in equation (1) being each of the cost variables in turn. We report results for the natural logarithm of costs to avoid sensitivity to extreme outliers in the levels of costs and to obtain estimates that approximate the effects of independent variables, and in particular provider choice policies, on percentage differences in costs. ${ }^{23}$ With this specification, the regression coefficients can be interpreted as the semi-elasticity-i.e., the percentage change in the outcome for a one-unit change in the independent variables (most importantly, differences in which provider choice policy prevails). ${ }^{24}$

We also report estimates from quantile regressions, which provide information on whether provider choice policies have different effects in different parts of the distributions of medical or indemnity costs. The policies may matter more in the upper tails of the distributions where treatment might be more extensive, costs might be high because of responses to incentives under different provider choice policies, etc. Quantile regressions estimated for the $90^{\text {th }}, 95^{\text {th }}$, or $99^{\text {th }}$ percentile might reveal some cost differences associated with provider choice policies that OLS or median regressions do not reveal.

One issue in this application of quantile regression is whether we want to estimate conditional or unconditional quantile regressions. Unconditional regressions would simply tell us whether, for example, the effect of provider choice policies on the level of costs at the $95^{\text {th }}$ percentile is different than at the $50^{\text {th }}$ percentile. Conditional versions of quantile regressions would ask whether this is true for similar claims-

\footnotetext{
${ }^{23}$ Since indemnity costs are zero for cases with medical-only benefits, we increase indemnity measures by $\$ 1$ before taking the natural logarithm to avoid dropping medical-only cases from the analysis.

${ }^{24}$ When the independent variable of interest is a dummy variable - as in our application where we are estimating the effects of different regimes for provider choice - the calculation is a bit more complex because the percentage change interpretation only holds precisely for small changes in the independent variable. Formally, for a coefficient $b$ on a dummy variable, the implied percentage change in our log-linear specification is $100 \cdot\left[e^{b}-1\right]$. This is very close to the same magnitude when $b$ is small, but the simple semi-elasticity interpretation becomes more inaccurate as $b$ gets large, although it remains qualitatively similar. Rather than reporting $100 \cdot\left[e^{b}-1\right]$ for our estimated effects of provider choice policies, we report the implied semi-elasticity, so that the textual description of our results matches the estimates reported in the table. To give some idea as to the range of approximation error, a reported semi-elasticity of 5 percent or 10 percent contains almost no approximation error ( 0.1 and 0.6 percent, respectively), but this error is larger for a reported elasticity of 25 or 50 percent ( 3.4 and 14.8 percent, respectively). Thus, for estimated semielasticities under 25 or 30 percent, which covers all but a few of the estimates we report, the approximation error is fairly negligible.
} 
with "similar" defined in terms of our control variables of worker characteristics, firm characteristics, injury types, etc. For example, if back injuries are the most expensive types of injuries and, hence, are overrepresented in the upper tail of the distribution of costs, then an unconditional quantile regression estimated at a high percentile would in large part reflect the effects of provider choice policies on the costs associated with back injuries. In contrast, conditional quantile regressions tell us about the effects of provider choice policies on the given percentile for cases with the same values of the variables on which we condition.

Thus, for example, if we condition on injury type, the $95^{\text {th }}$ percentile regression would tell us equally about the effects of provider choice policies on back injuries and other lower-cost injuries, with the effect identified from the data at the $95^{\text {th }}$ percentile of the distributions of costs for each type of injury.

To put this in concrete terms, suppose, for example, that one thought that policies giving workers greater control of the choice of provider opened up opportunities for injured workers to shop for a provider that would let them stay out of work longer. If this is only an issue for costlier cases with considerable subjectivity in diagnosis, like back injuries (or other expensive cases that can sometimes crop up with other injuries), the $95^{\text {th }}$ percentile regression without conditioning on type of injury might be of most interest. If, instead, worker choice drives up costs for the costlier cases relative to that injury, then the $95^{\text {th }}$ percentile regression conditional on injury type is most informative.

Given these possibilities, we report two sets of estimates. We always estimate our models conditioning on worker and firm characteristics. But we first report estimates that do not condition on injury type, and then we go to the opposite extreme and estimate separate models on subsamples of injury types (which condition on injury type, but also allow other model parameters to vary by injury type).

One has to exercise caution in interpreting the estimates from the models described above as causal. We do not have quasi-experimental evidence on the effects of provider choice policies — such as we could get from a longitudinal analysis based on observing some states changing their policies and other similar states not changing their policies. Instead, the effects of these policies are identified from cross-state policy variation. This may raise a concern that the associations we estimate are not causal because differences across states in provider choice policies are associated with other sources of cost differences across states. There are, however, reasons why a causal interpretation is plausible. 
First, we have detailed control variables, including a vector of key workers' compensation policies that should affect medical and indemnity costs, and which usually have the expected effects. Second, the most likely challenge to a causal interpretation of our findings would be that provider choice policies are endogenously determined. For example, policies granting employers more control of the choice of provider may be adopted in high-cost states in order to help rein in costs. If we then observe a state where policy gives employers control of the choice of provider but costs are high because policy implementation and impacts evolve slowly, we might find spurious evidence that policies giving employers more control of the choice of provider raise workers' compensation costs. ${ }^{25}$ But our data cover a period of time during which, by and large, provider choice policies have been in place for a long time, so if policies giving employers more control of provider choice are still associated with higher costs, a more plausible interpretation would be that policies restricting worker choice do not rein in costs. ${ }^{26}$

On the other hand, California and Texas adopted changes more recently (just prior to our sample period) that restrict worker choice to networks. Given that these recent reforms could generate biases from endogenous policy change, including these states in our analysis could generate variation between provider choice policies and costs that reflects the drivers of policies rather than the effects of those policies. ${ }^{27}$ To avoid this potential bias, these two states are dropped from the analysis.

\section{Evidence on the Effects of Provider Choice Policies}

\section{Descriptive statistics}

Tables $4 \mathrm{a}$ and $4 \mathrm{~b}$ report descriptive statistics for medical costs across states with different provider choice policies. Table 4a reports average (mean) medical costs — incurred and developed (along with the development factor) — using our two-way classification of state provider choice policies. These measures are an average of the state-level measures, giving observations from each state an equal influence on the

\footnotetext{
${ }^{25}$ Note, also, that an implication of this argument is that panel data on states with policy changes, which would allow the inclusion of fixed state effects, would not necessarily provide a more reliable causal estimate, unless we were sure that the "post-policy-change" period reflects the full cost impacts of the policy changes.

${ }^{26}$ In our view, there are no good instrumental variables for provider choice policies that could more definitively address policy endogeneity; this is typically the case for research using cross-jurisdictional policy variation.

${ }^{27}$ We do not have similar concerns about other workers' compensation policies that are included as controls for key state system features, for which implementation is surely much quicker. The effect of fee schedules can be virtually instantaneous (see Yang and Fomenko, 2014; and Fomenko and Yang 2015), and the adoption of utilization guides or treatment guides is also typically very fast.
} 
overall mean. Average costs were higher for developed costs than incurred costs. Table 4a points to slightly higher average costs in states where policies give workers relatively more control over the choice of provider. For incurred costs, the difference in state averages is higher by about $\$ 600$. For developed costs, the difference is just over $\$ 1,400$. The larger average difference for developed costs in the states where policies give workers more control is also reflected in the development factors, which were higher for states where policies give workers more control of the choice of provider, indicating that costs developed more slowly in these states.

Table $4 \mathrm{~b}$ reports instead the $90^{\text {th }}, 95^{\text {th }}$, and $99^{\text {th }}$ percentiles of the distributions of incurred and developed medical costs for each group of states. There is some evidence of higher costs in states where policies give workers more control over the choice of provider, at the upper percentiles, for both incurred and developed costs. For example, the average difference in developed costs is just over $\$ 1,400$; the difference is around $\$ 2,100$ at the $90^{\text {th }}$ percentile, $\$ 7,300$ at the $95^{\text {th }}$ percentile, and $\$ 32,000$ at the $99^{\text {th }}$ percentile. Note, however, that these absolute cost differences are more similar in terms of percentages. For example, in the last column of Table $4 \mathrm{~b}$, the ratio of developed medical costs at the $99^{\text {th }}$ percentile between states where policies give workers more control of the choice of provider and states where policies give employers the most control is 1.33 . The corresponding ratio for the means shown in Table 4a is 1.23.

These descriptive statistics suggest that although, on average, there are modest medical cost differences between states with policies that give workers more control or less control over the choice of provider, the high-cost cases in the states where policies give workers more control are more expensive than the high-cost cases in the states where policies most restrict worker choice of the provider. These findings motivate some of the richer distributional analyses that look beyond mean differences in costs associated with provider choice policies.

Tables $5 \mathrm{a}$ and $5 \mathrm{~b}$ present the same type of information, but for indemnity costs. In this case, across states, average incurred and developed costs are higher in states where policies give more control of the choice of provider to workers - by about $\$ 1,100$ for incurred costs and, because the average development factor in these states is larger, by about $\$ 1,800$ for developed costs. We also see that the development factors were smaller than they were for medical costs. In Table 5b, we find that, as for medical costs, at the 
upper tails of the distributions of these different indemnity cost measures, the cost differential in states where policies give workers more control over the choice of provider grows relative to the averages. In particular, evidence of higher costs in states where policies give workers more control over the choice of provider is more apparent at the upper percentiles, for both incurred and developed costs. For example, whereas the average difference in developed costs was around $\$ 1,800$ higher in these states, the difference is around $\$ 1,500$ at the $90^{\text {th }}$ percentile, $\$ 7,200$ at the $95^{\text {th }}$ percentile, and $\$ 46,000$ at the $99^{\text {th }}$ percentile. These higher costs in the upper tails of the distributions of costs are more evident for developed than for incurred costs. Again, however, these absolute cost differences are more similar in terms of percentages. ${ }^{28}$

\section{Multivariate OLS estimates}

We next turn to estimates from multivariate models for medical costs and indemnity costs, which hold constant characteristics of workers, employers, injuries, and workers' compensation systems. Table 6 reports results for the differences in medical costs. To interpret the magnitudes, the estimate of -1.6 in the first column, for example, implies that incurred medical costs in states where workers have more control over provider choice are approximately 1.6 percent lower than when employers have more control (the base category).

Table 6 shows estimates for incurred and developed medical costs. These estimates tell a consistent story - there is essentially no difference in average costs between the states where provider choice policies give workers the most control over the choice of provider, relative to the reference category of states where employers have the most control. The estimate is 1.6 percent lower incurred medical costs and 0.5 percent lower developed medical costs in states where policies give workers more control of the choice of provider. These estimates are not statistically significant at the 10 percent level, which is not surprising given their very small magnitudes. Note that these estimates differ a bit from the simple comparisons of averages across states based on their provider choice policies, where costs were slightly higher in states where policies give workers more control of the choice of provider. The difference is not surprising, however,

\footnotetext{
${ }^{28}$ The differences for both medical and indemnity costs depending on whether we look at incurred or developed costs are reflected in the development of both medical and indemnity costs. The percentages of incurred and developed medical and indemnity costs paid out by 36 months were lower for medical and indemnity costs in states where workers have most control of over the choice of provider.
} 
because we have added controls for other aspects of workers' compensation policies and for injury, worker, and firm characteristics. ${ }^{29}$

For indemnity costs, the point estimates in Table 7 suggest higher costs in states where policies give workers more control over the choice of provider. For both incurred and developed indemnity costs, the estimates indicate that costs are higher by about 20 percent in these states compared with the mostrestrictive employer choice states. ${ }^{30}$ However, these estimated cost differentials are not statistically significant.

\section{Quantile regression estimates}

We now turn to evidence from quantile regressions that tell us whether provider choice policies shift costs in the upper tails of the distributions of costs, without necessarily generating broader shifts in average costs (reflected in the conventional OLS regressions). Our estimates for the $90^{\text {th }}, 95^{\text {th }}$, and $99^{\text {th }}$ percentiles can be approximately interpreted as the differences in costs associated with different provider choice policies for the most expensive cases — those delineating the top 10 percent, top 5 percent, and top 1 percent costliest cases.

Table 8 presents results for medical costs for specifications that do not condition on type of injury, which are more informative about whether provider choice policies shift costs for higher-cost injuries or for lower-cost injuries. Later, we present results broken out by injury category, which tell us more about whether provider choice policies shift costs in the tails of the distributions of costs and whether those injuries tend to be higher- or lower-cost injuries.

Recall from Table 6 that, in the OLS regressions, the estimated differences in incurred and developed medical costs between the two sets of states classified by worker control over the choice of provider were close to zero (and statistically insignificant). The quantile regression estimates are more

\footnotetext{
${ }^{29}$ Our results are dependent on the reliability of the medical cost data. The full model estimates indicate that the other findings for medical costs are as expected. For example, injuries expected to be less expensive (e.g., other sprains and strains, and inflammations) are in fact estimated to be less expensive; and injuries expected to be more expensive are estimated to be more expensive, such as injuries to older workers, injuries in states without fee schedules, and injuries in states with a larger (positive) gap between the fee schedule and the Medicare rate

${ }^{30}$ The corresponding full model estimates generally reveal expected differences-such as higher indemnity costs for older workers, for upper extremity neurologic pain, and in states with higher temporary disability replacement rates.
} 
indicative of higher costs in states where policies give workers more control of the choice of provider. For incurred medical costs the differences range from 4.7 to 8.0 percent, and for developed medical costs they range from 10.9 to 14.7 percent. However, none of these estimated differentials are statistically significant.

The estimates for the same specifications and samples, but for indemnity instead of medical costs, are reported in Table 9. Recall the evidence from Table 7 that showed higher costs in states where policies give workers more control of the choice of provider, although the differences were not statistically significant. The estimated differences in Table 9 are actually smaller than those in Table 7, with the exception of developed indemnity costs at the $99^{\text {th }}$ percentile, although the point estimate is not a great deal larger than the average difference (27.9 versus 20.6). However, the point estimate for higher developed indemnity costs in the upper tail (the $99^{\text {th }}$ percentile) is statistically significant at the 10 percent level, providing statistical evidence that the highest-cost cases are more expensive in states where policies give workers more control over the choice of provider.

Overall, looking at the upper tails of the cost distributions, there is still little or no evidence that medical costs are higher in states where policies give workers more control of the choice of provider. But for indemnity costs, we find some evidence of higher costs among the most expensive cases in states where policies give workers more control over provider choice. ${ }^{31}$

Costs vary considerably across different types of injuries, and there may be more scope for provider choice policies to matter more for the higher-cost injuries, perhaps because of the greater complexity of treatment and subjectivity about workers' readiness to return to work. Table 10 documents this variation in cost by injury group. For example, average developed medical costs per claim ranged from

\footnotetext{
${ }^{31}$ Recall that our baseline OLS regressions of the effects of provider choice policies on medical and indemnity costs, in Tables 6 and 7, specify the dependent variable in natural logarithms (as do all the other specifications we have reported). The evidence that the effects of policies that give workers more control over the choice of provider are more positive (although rarely statistically significant) in the upper tails of the cost distributions suggests that the baseline regressions could, in principle, give results of the opposite (i.e., positive) sign if we specified the models in levels instead of logs. The reason is that equal percentage differences in costs represent larger absolute differences in costs when costs are high, and the quantile regressions for the upper tails of the cost distributions tell us that the percentage differences are higher at higher levels of costs. In tables available from the authors upon request, we show that the estimates of the baseline OLS specifications in levels are consistent with our results in logs. For medical costs, the estimates are negative and not statistically different from zero. For indemnity costs, the estimates are positive but are again not statistically different from zero, which parallels our findings in Table 7. Based on this evidence, using logs of costs but showing results for OLS, and at the $90^{\text {th }}, 95^{\text {th }}$, and $99^{\text {th }}$ percentiles, provides a comprehensive view of cost differences associated with provider choice policies.
} 
a low of $\$ 1,787$ for lacerations and contusions to a high of $\$ 13,154$ for fractures. These two types of injuries also had the lowest and highest averages for incurred medical costs. For indemnity costs, lacerations and contusions also had the lowest costs, while costs were highest for upper extremity neurologic pain (carpal tunnel), driven primarily by a higher percentage of claims with more than seven days of lost time.

We, therefore, next report estimates of specifications like those discussed in Tables 8 and 9, but for subsamples grouped by the injury categories in Table 10. Beginning with medical costs in Table 11, for each of the two cost measures and each injury type, we first report the OLS regression estimates that correspond to those reported in Table 6, and we then report the quantile regression estimates that correspond to those in Table 8.

Looking at the OLS estimates, for all injury types but one (back and neck sprains, etc.), the point estimates suggest slightly lower incurred or developed medical costs in states where provider choice policies give workers more control of the choice of provider. The estimated differentials are often close to zero, and none are statistically significant.

Looking at the upper tails of the cost distributions for each injury (the $90^{\text {th }}, 95^{\text {th }}$, and $99^{\text {th }}$ percentile regressions), the estimates for incurred medical costs are not very different. Most of the estimates are still negative, consistent with lower costs in states where policies give workers more control of the choice of provider, although the estimates become positive for other sprains and strains. There is one injury typelacerations and contusions - for which there is evidence of significantly lower medical costs in states where policies give workers more control over the choice of provider (by 15.7 percent, for both incurred and developed costs, at the $90^{\text {th }}$ percentile). For developed medical costs, in contrast, many more estimates are positive, consistent with higher medical costs. In particular, there are some rather large estimated cost differences for back and neck sprains, strains, and non-specific pain, or neurologic spine pain, especially at the $90^{\text {th }}$ percentile - where the positive estimate is statistically significant. ${ }^{32}$ For the most part, though, there

\footnotetext{
${ }^{32}$ The back-related injuries included in our analysis reflect about 18 percent of the sample of workers' compensation claims that we examined, while the costliest 10 percent of the back-related cases highlighted in the analysis reflect less than 2 percent of the sample.
} 
is no strong evidence of higher medical costs in states where policies give workers more control over the choice of provider. For many of the injury types, the estimates of upper-tail cost differentials are relatively small and statistically insignificant.

Table 12 turns to the evidence on incurred and developed indemnity costs. Here, too, we begin with OLS estimates (this time paralleling Tables 7 and 9) for each injury group. Recall that in Table 7 we found positive estimates around 20 percent for provider choice policies giving workers more control over the choice of provider, but these estimates were not statistically significant. The estimates in Table 12 point to quite a bit of heterogeneity across injury types. For the OLS estimates, the estimated differentials point to higher costs in states where policies give workers more control of the choice of provider, in every case but one (upper extremity neurologic pain, for developed indemnity costs). For some injuries, the estimated cost differentials are small (lacerations and contusions, and inflammations), whereas for others they are quite large (back and neck sprains, strains, and non-specific pain, or neurologic spine pain, and other sprains and strains). But these estimated differences are never statistically significant.

When we look at the estimates at the upper percentiles of the cost distributions, there are isolated cases where some differences appear. This is most notable for the $99^{\text {th }}$ percentile for back and neck sprains, strains, and non-specific pain, or neurologic spine pain, where the estimate becomes positive and rather large for developed indemnity costs (31.1 percent) — the one estimate for upper-tail costs that is statistically significant. In general, though, this analysis also does not lead to strong evidence of cost differences between states based on the extent to which policies provide either employers or workers with the most control of the choice of provider. And for the most part — with one or two exceptions - there is not markedly different evidence at the upper tails of the cost distributions.

That said, across the various quantile regression estimates, there is one relatively consistent finding. For both medical and indemnity costs, for the injuries including back and neck sprains, strains, and non-specific pain, or neurologic spine pain, the upper tails of the cost distributions are higher in states where policies give workers more control of the choice of provider.

\section{Conclusions and Discussion}

We estimate the effects of state provider choice policies on workers' compensation medical and 
indemnity costs. We study how these policies affect incurred and developed costs. The findings indicate a nuanced view. On the one hand, the evidence generally points to essentially no difference in average medical costs between states where policies give employers control over the choice of provider and states where policies give workers the most control. We also present a richer distributional analysis that estimates the effects of provider choice policies in the upper tail of the distribution of medical costs. We find no statistical evidence of overall differences in medical costs for the costliest cases overall. But when we estimate the cost differences in the upper tail by injury type, for the injury grouping that includes back and neck sprains, strains, and non-specific pain, or neurologic spine pain, there is statistically significant evidence of higher incurred and/or developed medical costs in the most expensive cases in states where policies give workers more control over the choice of provider.

Between the absence of differences for average costs, the absence of differences for the high-cost cases for many types of injuries, and the evidence of some cost differences in offsetting directions, there is by no means an overwhelming case for concluding that medical costs are higher when policies give workers more control over the choice of provider. However, there is fairly strong evidence that medical costs are higher for the injury grouping including back and neck sprains, strains, and non-specific pain, or neurologic spine pain.

The evidence is somewhat clearer for indemnity costs. For average costs, the evidence is in the direction of higher costs in the states where regulations allow workers to have the most control over provider choice. Incurred and developed costs are about 20-24 percent higher relative to states where employers have the most control, although these differences are not statistically significantly different from zero. By injury type, there is not statistically significant evidence of higher costs, on average, when policies give workers more control over the choice of provider. But when we examine the costliest cases, we find statistically significant evidence of higher developed indemnity costs when workers have the most control of choice of provider (at the $99^{\text {th }}$ percentile of the distribution of developed medical costs, by about $28-30$ percent). Similar analyses by injury group indicate that this cost difference is driven by the injury group that includes back and neck sprains, strains, and non-specific pain, or neurologic spine pain.

This evidence of higher indemnity costs for some injury groupings does not establish overall cost 
differences associated with whether workers or employers have more control over the choice of provider. On the other hand, especially for injuries including back and neck sprains, strains, and non-specific pain, or neurologic spine pain, these are the same types of injuries for which we find evidence of higher medical costs, among the costliest cases, in states where policies give workers the most control of the choice of provider. Thus, perhaps the strongest and most robust conclusion is that very costly back-related injuries tend to have both higher medical and indemnity costs in states where policies give workers more control over the choice of provider. And these injuries, which are relatively expensive, also appear to at least partially account for higher indemnity costs, overall, in the most expensive cases in states where policies give workers the most control over the choice of provider.

Simple economic hypotheses regarding the incentives of treating providers and workers might predict that average medical costs would be higher when policies give workers more control of the choice of provider, although other elements may be at play that can improve the efficacy of such policies. One possibility is that more worker control of the choice of the provider leads to better medical decision making, perhaps because of more trust between the patient and the treating provider, lower likelihood of disputes about care, and better information about the worker. Aside from greater trust when workers choose the treating provider, when the worker chooses a prior provider, the knowledge that provider has about the worker may lead to better and more effective treatment decisions. ${ }^{33}$ It may be that the absence of evidence of average medical cost differences associated with giving workers or employers more control over the choice of provider is accounted for by these offsetting influences.

At the same time, the evidence indicates that there is a greater number of cases with high indemnity (and in some cases medical) costs when policies give workers more control over the choice of the provider, for back-related injuries. This effect in the upper tails of the cost distributions could reflect some of the common criticisms of policies giving workers more control - that such policies remove the incentive to

\footnotetext{
${ }^{33}$ The latter hypothesis may to some extent parallel the findings from Neumark et al. (2007), who found that when workers chose the provider and that provider was one with whom they had a prior relationship, medical costs and time out of work were no higher than when employers chose the provider. It seems likely that, on average, when employers choose or control the choice of provider, the worker generally will not be treated by a provider with whom the worker has a prior medical relationship.
} 
hold down costs, and that workers can collaborate with their providers to stay out of work longer.

With regard to policy, given that average costs are not higher when policies give workers more control of the choice of provider, policy changes that restrict worker choice across the board (as a means of addressing the problem of some fraction of cases leading to very high costs when policies give workers control of the choice of provider) may well fail to reduce costs on average. However, there might be more scope for cost reduction from focusing on how to reduce the incidence of some of the highest-cost cases when policies give workers control of the choice of provider. Policies giving employers more control over the choice of provider may be more effective at tamping down high-cost cases than at lowering costs in more-routine cases. Other cost-containment measures, such as treatment guidelines, might do more to reduce costs when policies give workers more control of the choice of provider; however, analyzing these kinds of program interactions is difficult given the small number of states from which the effects of particular combinations of provider choice policies and other policies could be estimated.

Moreover, our research is limited to the relationships between provider choice policies "on the books" and workers' compensation medical and indemnity costs. Understanding how implementation of provider choice policies affects costs and, even more so, how policymakers can influence implementation - rather than just writing statutes — is a formidable challenge. Finally, it is important to extend the research beyond costs, which are by no means the only desiderata in judging the effectiveness of workers' compensation policies. Ultimately, we also need evidence on the benefits of alternative policies in terms of productive return to work of injured workers. 


\section{References}

Barth, P., and M. Niss. 1999. Permanent partial disability benefits: Interstate differences. Cambridge, MA: Workers Compensation Research Institute.

Boden, L. 1992. Workers compensation medical costs: A special case. In J. Greenwood and A. Taricco (eds.), Workers compensation health care cost containment (pp. 27-54). Horsham, PA: LRP Publications.

Boden, L., and C. Fleischman. 1989. Medical costs in workers' compensation: Trends and interstate comparisons. Cambridge, MA: Workers Compensation Research Institute.

Durbin, D., and D. Appel. 1991. The impact of fee schedules and employer choice of physician. NCCI Digest 6 (3): 39-59.

Elam, K., V. Taylor, M. Ciol, G. Franklin, and R. Deyo. 1997. Impact of a Worker's Compensation Practice Guideline on Lumbar Spine Fusion in Washington State. Medical Care 35 (5), 417-424.

Ellenberger, J. 1992. Labor's perspective on health care reform. In J. Greenwood and A. Taricco (eds.), Workers compensation health care cost containment (pp. 245-260). Horsham, PA: LRP Publications.

Fomenko, O., and T. Liu. 2012. Designing workers' compensation medical fee schedules. Cambridge, MA: Workers Compensation Research Institute.

Fomenko, O., and R. Victor. 2013. A new benchmark for workers' compensation fee schedules: Prices paid by commercial insurers. Cambridge, MA: Workers Compensation Research Institute.

Fomenko, O., and R. Yang. 2015. Hospital outpatient costs index for workers' compensation, 4th edition. Cambridge, MA: Workers Compensation Research Institute.

Machado, J., P. Parente, and J. Santos Silva. 2013. QREG2: Stata module to perform quantile regression with robust and clustered standard errors, Statistical Software Components S457369, Boston College Department of Economics.

Morrison, J. 1990. Medical cost containment for workers' compensation. Journal of Risk and Insurance 57 (4): 646-653.

National Council on Compensation Insurance (NCCI). 2014. Annual statistical bulletin.

National Federation of Independent Business Research Foundation and National Foundation for Unemployment Compensation and Workers' Compensation. n.d. Legislative guide to workers' compensation insurance reform in the states.

Neumark, D., and B. Savych. 2017. The Effects of Provider Choice Policies on Workers' Compensation Outcomes. Cambridge, MA: Workers Compensation Research Institute.

Neumark, D., P. Barth, and R. Victor. 2007. The impact of provider choice on workers' compensation costs and outcomes. Industrial and Labor Relations Review 61 (1): 121-142.

Parente, P., and J. Santos Silva. 2013. Quantile regression with clustered data. Department of Economics, University of Essex, Discussion Paper No 728.

Pozzebon, S. 1994. Medical cost containment under workers' compensation. Industrial and Labor Relations Review 48 (1): 153-167.

Shraim, M., M. Cifuentes, J. Willetts, H. Marucci-Wellman, and G. Pransky. 2015. Length of disability and medical costs in low back pain: Do state workers' compensation policies make a difference? Journal of Occupational and Environmental Medicine 57 (12): 1,275-1,283.

Tanabe, R. 2010. Workers' compensation laws as of January 2010. Cambridge, MA: Workers Compensation Research Institute.

Tanabe, R. 2011. Workers' compensation medical cost containment: A national inventory, 2011. Cambridge, MA: Workers Compensation Research Institute.

Telles, C. 2016. CompScope ${ }^{\mathrm{TM}}$ benchmarks for North Carolina, 16th edition. Cambridge, MA: Workers Compensation Research Institute.

U.S. Chamber of Commerce. 2010. 2010 analysis of workers' compensation laws. Washington, DC.

Victor, R., P. Barth, D. Neumark, and T. Liu. 2005. The impact of provider choice on workers' compensation costs and outcomes. Cambridge, MA: Workers Compensation Research Institute. 
Victor, R., and C. Fleischman. 1990. How choice of provider and recessions affect medical costs in workers' compensation. Cambridge, MA: Workers Compensation Research Institute.

Washington Department of Labor and Industries and University of Washington Department of Health Services. 1997. Workers' compensation managed care pilot project: Final report to the legislature.

Welch, E. 2008. Permanent partial disability benefits. Michigan State University, School of Labor and Industrial Relations Working Paper.

Workers Compensation Research Institute (WCRI), International Association of Industrial Accident Boards and Commissions (IAIABC). 2009. Workers' compensation laws, 2nd edition. Cambridge, MA: Workers Compensation Research Institute.

Yang, R. 2013. CompScope ${ }^{\mathrm{TM}}$ benchmarks for Florida, 14th edition. Cambridge, MA: Workers Compensation Research Institute.

Yang, R. 2016. CompScope ${ }^{\text {TM }}$ benchmarks for Florida, 16th edition. Cambridge, MA: Workers Compensation Research Institute.

Yang, R., and O. Fomenko. 2014. WCRI medical price index for workers' compensation, sixth edition (MPI-WC). Cambridge, MA: Workers Compensation Research Institute. 
Table 1. Provider Choice Regulations in Study States, 2007-2010

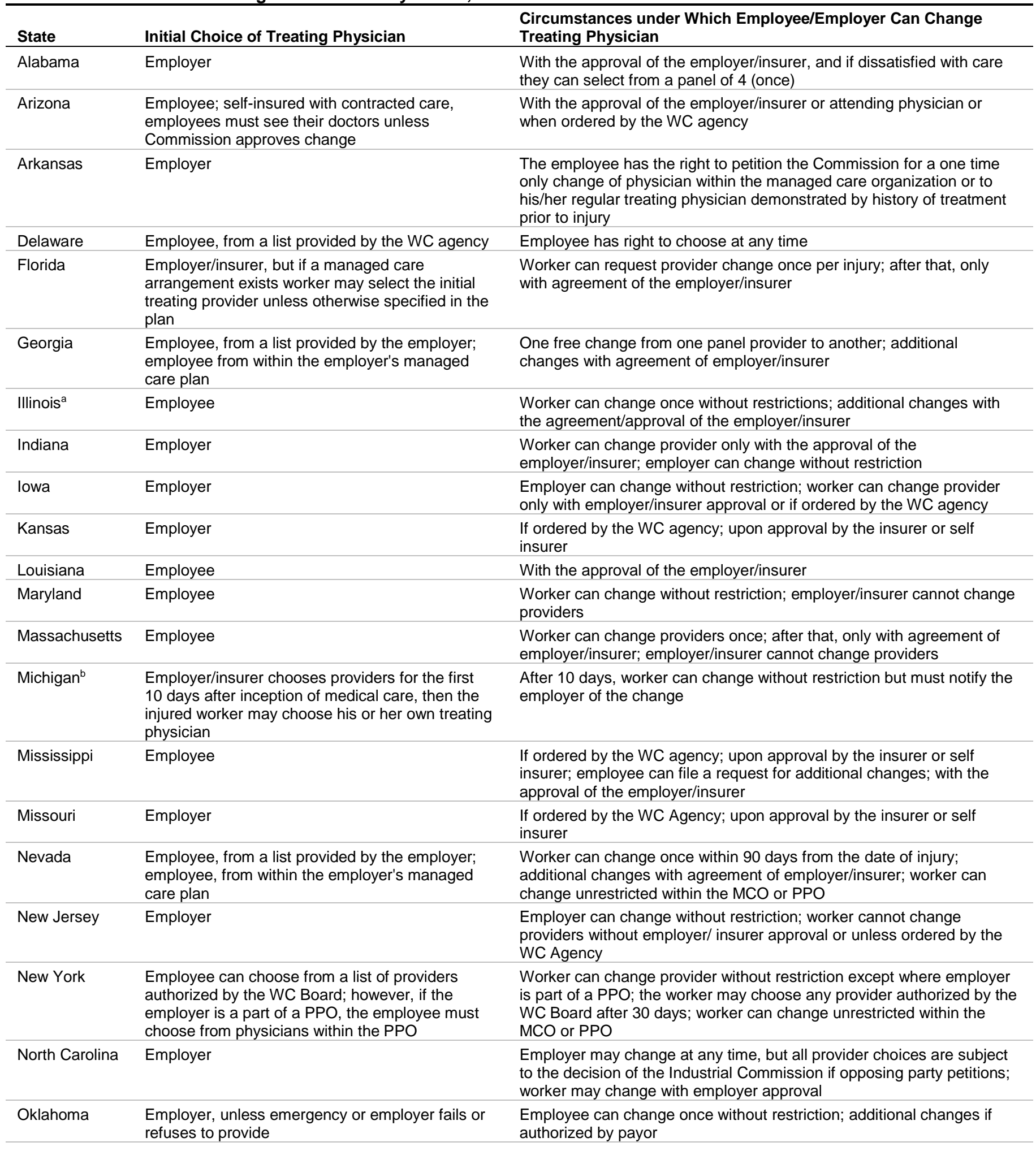


Table 1 (cont.). Provider Choice Regulations in Study States, 2007-2010 (continued)

\begin{tabular}{lll}
\hline State & Initial Choice of Treating Physician & $\begin{array}{l}\text { Circumstances under Which Employee/Employer Can Change } \\
\text { Treating Physician }\end{array}$ \\
\hline $\begin{array}{l}\text { South } \\
\text { Carolina }\end{array}$ & Employer & $\begin{array}{l}\text { Employer can change without restriction; worker cannot change } \\
\text { providers without employer/insurer approval }\end{array}$ \\
\hline Tennessee & $\begin{array}{l}\text { Employee from a list of three or more providers } \\
\text { provided by the employer }\end{array}$ & $\begin{array}{l}\text { Worker can change only with approval of employer/insurer; employer } \\
\text { may request a change of physician with the state WC Agency's approval }\end{array}$ \\
\hline Virginia & $\begin{array}{l}\text { Employee, from a panel of physicians provided by } \\
\text { the employer }\end{array}$ & $\begin{array}{l}\text { Worker can change upon approval by the employer/insurer or if ordered } \\
\text { by the WC Commission; if either party wants to change treating } \\
\text { physicians and there is no agreement, the Commission can decide }\end{array}$ \\
\hline Wisconsin & Employee & $\begin{array}{l}\text { Workers can change once without restriction; subsequent changes } \\
\text { require agreement of the employer/insurer; employer/insurer cannot } \\
\text { change providers }\end{array}$ \\
\hline
\end{tabular}

a 2011 reforms in Illinois introduced a preferred provider program for selecting treating physicians. The final rules regarding the use of preferred provider programs were adopted in March 2013. This policy change was outside the sample period studied.

${ }^{b}$ Effective for injuries after December 19, 2011, the employer control of providers was extended to 28 days. This change was outside the sample period examined in the study.

Key: MCO: managed care organization; PPO: preferred provider organization; WC: workers' compensation.

Sources: State statutes; WCRI and IAIABC (2009); Tanabe (2010, 2011).

Table 2. Study States by Provider Choice Policy Group, Two-Way Classification, 2007-2010

\begin{tabular}{|c|c|}
\hline Group of States & States \\
\hline $\begin{array}{l}\text { States with employer choice of provider or } \\
\text { employer control of panel, with very } \\
\text { restricted options for workers to change } \\
\text { provider }\end{array}$ & $\begin{array}{l}\text { Alabama, Arkansas, Florida, Georgia, Indiana, lowa, Kansas, Missouri, } \\
\text { Nevada, New Jersey, North Carolina, Oklahoma, South Carolina, } \\
\text { Tennessee, Virginia }\end{array}$ \\
\hline $\begin{array}{l}\text { States with worker choice or workers have } \\
\text { considerable ability to change provider }\end{array}$ & $\begin{array}{l}\text { Arizona, Delaware, Illinois, Louisiana, Maryland, Massachusetts, Michigan, } \\
\text { Mississippi, New York, Wisconsin }\end{array}$ \\
\hline \multicolumn{2}{|c|}{$\begin{array}{l}\text { Notes: Two states made changes in provider choice regulations a short time prior to our analysis window and, thus, are not } \\
\text { included in this classification. Texas introduced network regulations effective January 2006. California allowed creation of } \\
\text { medical networks effective January } 2005 \text {. }\end{array}$} \\
\hline \multicolumn{2}{|c|}{$\begin{array}{l}\text { Two states made changes in provider choice regulations after our analysis window. Michigan expanded employer control } \\
\text { of provider choice from } 10 \text { to } 28 \text { days in } 2011 \text {. Illinois introduced a preferred provider program for selecting treating } \\
\text { physicians in } 2011 \text { (the final rules were adopted in March 2013). }\end{array}$} \\
\hline
\end{tabular}


Table 3. Additional Workers' Compensation Policies and Regulations in Study States (as of 2010)

\begin{tabular}{|c|c|c|c|c|c|c|}
\hline State & $\begin{array}{c}\text { Individual } \\
\text { Replacement } \\
\text { Rate (sample } \\
\text { average) }\end{array}$ & $\begin{array}{c}\text { Wage-Loss } \\
\text { System }\end{array}$ & $\begin{array}{c}\text { Fee Schedule } \\
\text { for } \\
\text { Professional } \\
\text { Services }\end{array}$ & $\begin{array}{c}\text { Fee Schedule } \\
\text { Rates as \% } \\
\text { over } \\
\text { Medicare, } \\
\text { Overall }\end{array}$ & $\begin{array}{c}\text { Treatment } \\
\text { Guidelines } \\
\text { (mandatory) }\end{array}$ & $\begin{array}{c}\text { Utilization } \\
\text { Review } \\
\text { Required }\end{array}$ \\
\hline Alabama & $67 \%$ & No & Yes & $73 \%$ & No & No \\
\hline Arizona & $58 \%$ & Yes & Yes & $71 \%$ & No & No \\
\hline Arkansas & $64 \%$ & No & Yes & $59 \%$ & No & Yes \\
\hline Delaware & $66 \%$ & No & Yes & $120 \%$ & No & No \\
\hline Florida & $65 \%$ & No & Yes & $6 \%$ & Yes & Yes \\
\hline Georgia & $63 \%$ & Yes & Yes & $73 \%$ & No & No \\
\hline Illinois & $69 \%$ & No & Yes & $158 \%$ & No & No \\
\hline Indiana & $65 \%$ & No & No & $\mathrm{n} / \mathrm{a}$ & No & No \\
\hline lowa & $67 \%$ & No & No & $\mathrm{n} / \mathrm{a}$ & No & No \\
\hline Kansas & $62 \%$ & No & Yes & $52 \%$ & No & No \\
\hline Louisiana & $64 \%$ & Yes & Yes & $58 \%$ & No & Yes \\
\hline Maryland & $66 \%$ & No & Yes & $27 \%$ & No & No \\
\hline Massachusetts & $64 \%$ & Yes & Yes & $4 \%$ & Yes & Yes \\
\hline Michigan & $63 \%$ & Yes & Yes & $40 \%$ & No & Yes \\
\hline Mississippi & $61 \%$ & No & Yes & $69 \%$ & No & Yes \\
\hline Missouri & $66 \%$ & No & No & $\mathrm{n} / \mathrm{a}$ & No & No \\
\hline Nevada & $55 \%$ & No & Yes & $105 \%$ & Yes & No \\
\hline New Jersey & $70 \%$ & No & No & $\mathrm{n} / \mathrm{a}$ & No & No \\
\hline New York & $62 \%$ & No & Yes & $20 \%$ & No & No \\
\hline North Carolina & $66 \%$ & Yes & Yes & $23 \%$ & No & Yes \\
\hline Oklahoma & $68 \%$ & No & Yes & $41 \%$ & Yes & No \\
\hline South Carolina & $65 \%$ & No & Yes & $45 \%$ & No & No \\
\hline Tennessee & $67 \%$ & No & Yes & $65 \%$ & No & Yes \\
\hline Virginia & $69 \%$ & Yes & No & $\mathrm{n} / \mathrm{a}$ & No & No \\
\hline Wisconsin & $66 \%$ & No & No & $\mathrm{n} / \mathrm{a}$ & No & No \\
\hline
\end{tabular}

Key: n/a: not applicable.

Sources: State statutes; WCRI and IAIABC (2009); Tanabe (2010, 2011); U.S. Chamber of Commerce (2010). 
Table 4a. Average Incurred and Developed Medical Costs, and Development Factor, at 36 Months of Maturity, Injury Years 2007-2010, by Provider Choice Policy

\begin{tabular}{|c|c|c|c|}
\hline Group of States & $\begin{array}{c}\text { Incurred } \\
\text { Medical Costs }\end{array}$ & $\begin{array}{l}\text { Development } \\
\text { Factor }\end{array}$ & $\begin{array}{c}\text { Developed } \\
\text { Medical Costs }\end{array}$ \\
\hline $\begin{array}{l}\text { States with employer choice of provider or } \\
\text { employer control of panel, with very } \\
\text { restricted options for workers to change } \\
\text { provider }\end{array}$ & $\$ 5,060$ & 1.235 & $\$ 6,260$ \\
\hline $\begin{array}{l}\text { States with worker choice or workers have } \\
\text { considerable ability to change provider }\end{array}$ & $\$ 5,675$ & 1.342 & $\$ 7,694$ \\
\hline
\end{tabular}

Table $4 \mathrm{~b} .90^{\text {th }}, 95^{\text {th }}$, and $99^{\text {th }}$ Percentiles of Incurred and Developed Medical Costs at 36 Months of Maturity, Injury Years 2007-2010, by Provider Choice Policy

\begin{tabular}{|c|c|c|c|c|c|c|}
\hline \multirow[b]{2}{*}{ Group of States } & \multicolumn{3}{|c|}{ Incurred Medical Costs } & \multicolumn{3}{|c|}{ Developed Medical Costs } \\
\hline & $\begin{array}{c}90^{\text {th }} \\
\text { Percentile }\end{array}$ & $\begin{array}{c}95^{\text {th }} \\
\text { Percentile }\end{array}$ & $\begin{array}{c}99^{\text {th }} \\
\text { Percentile }\end{array}$ & $\begin{array}{c}90^{\text {th }} \\
\text { Percentile }\end{array}$ & $\begin{array}{c}95^{\text {th }} \\
\text { Percentile }\end{array}$ & $\begin{array}{c}99^{\text {th }} \\
\text { Percentile }\end{array}$ \\
\hline $\begin{array}{l}\text { States with employer choice of provider } \\
\text { or employer control of panel, with very } \\
\text { restricted options for workers to change } \\
\text { provider }\end{array}$ & $\$ 8,982$ & $\$ 20,203$ & $\$ 73,004$ & $\$ 9,393$ & $\$ 22,474$ & $\$ 98,283$ \\
\hline $\begin{array}{l}\text { States with worker choice or workers } \\
\text { have considerable ability to change } \\
\text { provider }\end{array}$ & $\$ 10,527$ & $\$ 23,790$ & $\$ 86,188$ & $\$ 11,501$ & $\$ 29,774$ & $\$ 130,393$ \\
\hline
\end{tabular}

Table 5a. Average Incurred and Developed Indemnity Costs, and Development Factor, at 36 Months of Maturity, Injury Years 2007-2010, by Provider Choice Policy

\begin{tabular}{lccc}
\hline Group of States & $\begin{array}{c}\text { Incurred } \\
\text { Indemnity Costs }\end{array}$ & $\begin{array}{c}\text { Development } \\
\text { Factor }\end{array}$ & $\begin{array}{c}\text { Developed } \\
\text { Indemnity Costs }\end{array}$ \\
\hline $\begin{array}{l}\text { States with employer choice of provider or } \\
\text { employer control of panel, with very restricted }\end{array}$ & & & \\
$\begin{array}{l}\text { options for workers to change provider } \\
\begin{array}{l}\text { States with worker choice or workers have } \\
\text { considerable ability to change provider }\end{array}\end{array}$ & $\$ 4,315$ & 1.139 & $\$ 5,000$ \\
\hline
\end{tabular}

Table 5b. $90^{\text {th }}, 95^{\text {th }}$, and $99^{\text {th }}$ Percentiles of Incurred and Developed Indemnity Costs at 36 Months of Maturity, Injury Years 2007-2010, by Provider Choice Policy

\begin{tabular}{|c|c|c|c|c|c|c|}
\hline \multirow[b]{2}{*}{ Group of States } & \multicolumn{3}{|c|}{ Incurred Indemnity Costs } & \multicolumn{3}{|c|}{ Developed Indemnity Costs } \\
\hline & $\begin{array}{c}90^{\text {th }} \\
\text { Percentile }\end{array}$ & $\begin{array}{c}95^{\text {th }} \\
\text { Percentile }\end{array}$ & $\begin{array}{c}9^{\text {th }} \\
\text { Percentile }\end{array}$ & $\begin{array}{c}90^{\text {th }} \\
\text { Percentile }\end{array}$ & $\begin{array}{c}95^{\text {th }} \\
\text { Percentile }\end{array}$ & $\begin{array}{c}99^{\text {th }} \\
\text { Percentile }\end{array}$ \\
\hline $\begin{array}{l}\text { States with employer choice of provider } \\
\text { or employer control of panel, with very } \\
\text { restricted options for workers to change } \\
\text { provider }\end{array}$ & $\$ 8,168$ & $\$ 22,610$ & $\$ 88,449$ & $\$ 8,583$ & $\$ 24,766$ & $\$ 105,226$ \\
\hline $\begin{array}{l}\text { States with worker choice or workers } \\
\text { have considerable ability to change } \\
\text { provider }\end{array}$ & $\$ 9,149$ & $\$ 27,200$ & $\$ 116,700$ & $\$ 10,047$ & $\$ 31,925$ & $\$ 151,437$ \\
\hline
\end{tabular}


Table 6. The Effects of Provider Choice Policies on Incurred and Developed Medical Costs, Injury Years 2007-2010, Estimates from OLS, Semi-Elasticities

\begin{tabular}{|c|c|c|}
\hline Group of States & $\begin{array}{l}\text { Incurred } \\
\text { Medical } \\
\text { Costs }\end{array}$ & $\begin{array}{l}\text { Developed } \\
\text { Medical } \\
\text { Costs }\end{array}$ \\
\hline
\end{tabular}

States with employer choice of provider or employer control of panel, with very restricted options for workers to change provider [base]

States with worker choice or workers have considerable ability to change provider $-1.6$ $-0.5$ Notes: Estimates are from OLS regressions relative to the base category of states with employer choice of provider or employer control of panel, with very restricted options for workers to change provider. Full set of estimate of regression coefficients are available from authors. Standard errors are estimated allowing for intra-state cluster correlation. ${ }^{* * *}$ statistically significant at $1 \%$ level, ${ }^{* *}$ statistically significant at $5 \%$ level, ${ }^{*}$ statistically significant at $10 \%$ level.

Table 7. The Effects of Provider Choice Policies on Incurred and Developed Indemnity Costs, Injury Years 2007-2010, Estimates from OLS, Semi-Elasticities

\begin{tabular}{|c|c|c|}
\hline Group of States & $\begin{array}{l}\text { Incurred } \\
\text { Indemnity } \\
\text { Costs }\end{array}$ & $\begin{array}{l}\text { Developed } \\
\text { Indemnity } \\
\text { Costs }\end{array}$ \\
\hline \multicolumn{3}{|l|}{$\begin{array}{l}\text { States with employer choice of provider or employer control of panel, with very } \\
\text { restricted options for workers to change provider [base] }\end{array}$} \\
\hline States with worker choice or workers have considerable ability to change provider & 19.2 & 20.6 \\
\hline
\end{tabular}

Table 8. Coefficient Estimates from Quantile Regressions for Incurred and Developed Medical Costs, Injury Years 2007-2010

\begin{tabular}{|c|c|c|}
\hline & $\begin{array}{l}\text { Incurred } \\
\text { Medical Costs }\end{array}$ & $\begin{array}{c}\text { Developed } \\
\text { Medical } \\
\text { Costs } \\
\end{array}$ \\
\hline \multicolumn{3}{|l|}{$90^{\text {th }}$ percentile } \\
\hline \multicolumn{3}{|l|}{$\begin{array}{l}\text { States with employer choice of provider or employer control of panel, with very } \\
\text { restricted options for workers to change provider [base] }\end{array}$} \\
\hline States with worker choice or workers have considerable ability to change provider & 8.0 & 11.4 \\
\hline \multicolumn{3}{|l|}{$95^{\text {th }}$ percentile } \\
\hline \multicolumn{3}{|l|}{$\begin{array}{l}\text { States with employer choice of provider or employer control of panel, with very } \\
\text { restricted options for workers to change provider [base] }\end{array}$} \\
\hline States with worker choice or workers have considerable ability to change provider & 8.0 & 14.7 \\
\hline \multicolumn{3}{|l|}{$99^{\text {th }}$ percentile } \\
\hline \multicolumn{3}{|l|}{$\begin{array}{l}\text { States with employer choice of provider or employer control of panel, with very } \\
\text { restricted options for workers to change provider [base] }\end{array}$} \\
\hline States with worker choice or workers have considerable ability to change provider & 4.7 & 10.9 \\
\hline \multicolumn{3}{|c|}{$\begin{array}{l}\text { Notes: Estimates are from quantile regressions relative to the base category of states with employer choice of provider or } \\
\text { employer control of panel, with very restricted options for workers to change provider. Full set of estimates is available } \\
\text { from authors upon request. Standard errors are estimated allowing for intra-cluster correlation as in Parente and Santos } \\
\text { Silva (2013), using qreg } 2 \text { estimation in Stata with state-level clustering (Machado, Parente, and Santos Silva, } 2013 \text { ). }{ }^{\star \star \star} \\
\text { statistically significant at } 1 \% \text { level, }{ }^{* \star} \text { statistically significant at } 5 \% \text { level, }{ }^{\star} \text { statistically significant at } 10 \% \text { level. }\end{array}$} \\
\hline
\end{tabular}


Table 9. Coefficient Estimates from Quantile Regressions for Incurred and Developed Indemnity Costs, Injury Years 2007-2010

\begin{tabular}{|c|c|c|}
\hline & $\begin{array}{l}\text { Incurred } \\
\text { Indemnity } \\
\text { Costs }\end{array}$ & $\begin{array}{l}\text { Developed } \\
\text { Indemnity } \\
\text { Costs }\end{array}$ \\
\hline \multicolumn{3}{|l|}{$90^{\text {th }}$ percentile } \\
\hline \multicolumn{3}{|l|}{$\begin{array}{l}\text { States with employer choice of provider or employer control of panel, with very } \\
\text { restricted options for workers to change provider [base] }\end{array}$} \\
\hline States with worker choice or workers have considerable ability to change provider & 8.0 & 13.4 \\
\hline \multicolumn{3}{|l|}{$95^{\text {th }}$ percentile } \\
\hline \multicolumn{3}{|l|}{$\begin{array}{l}\text { States with employer choice of provider or employer control of panel, with very } \\
\text { restricted options for workers to change provider [base] }\end{array}$} \\
\hline States with worker choice or workers have considerable ability to change provider & -3.4 & 5.8 \\
\hline \multicolumn{3}{|l|}{$99^{\text {th }}$ percentile } \\
\hline \multicolumn{3}{|l|}{$\begin{array}{l}\text { States with employer choice of provider or employer control of panel, with very } \\
\text { restricted options for workers to change provider [base] }\end{array}$} \\
\hline States with worker choice or workers have considerable ability to change provider & 12.4 & $27.9^{*}$ \\
\hline \multicolumn{3}{|c|}{$\begin{array}{l}\text { Notes: Estimates are from quantile regressions relative to the base category of states with employer choice of provider ol } \\
\text { employer control of panel, with very restricted options for workers to change provider. Full set of estimates is available } \\
\text { from authors upon request. Standard errors are estimated allowing for intra-cluster correlation as in Parente and Santos } \\
\text { Silva (2013), using qreg2 estimation in Stata with state-level clustering (Machado, Parente, and Santos Silva, 2013). }{ }^{* * *} \\
\text { statistically significant at } 1 \% \text { level, }{ }^{* *} \text { statistically significant at } 5 \% \text { level, }{ }^{*} \text { statistically significant at } 10 \% \text { level. }\end{array}$} \\
\hline
\end{tabular}

Table 10. Average Indemnity and Medical Payments at 36 Months of Maturity, Injury Years 2007-2010, by Injury Group

\begin{tabular}{|c|c|c|c|c|c|c|}
\hline Injury Group & $\begin{array}{c}\text { Incurred } \\
\text { Medical } \\
\text { Costs } \\
\end{array}$ & $\begin{array}{c}\text { Developed } \\
\text { Medical } \\
\text { Costs } \\
\end{array}$ & $\begin{array}{c}\text { Incurred } \\
\text { Indemnity } \\
\text { Costs } \\
\end{array}$ & $\begin{array}{c}\text { Developed } \\
\text { Indemnity } \\
\text { Costs }\end{array}$ & $\begin{array}{l}\text { \% Open } \\
\text { Claims }\end{array}$ & $\begin{array}{c}\% \text { of Claims } \\
\text { with More } \\
\text { Than } 7 \text { Days } \\
\text { of Lost Time }\end{array}$ \\
\hline Fractures & $\$ 10,716$ & $\$ 13,154$ & $\$ 8,495$ & $\$ 9,782$ & $7 \%$ & $50 \%$ \\
\hline Lacerations and contusions & $\$ 1,534$ & $\$ 1,787$ & $\$ 771$ & $\$ 886$ & $1 \%$ & $8 \%$ \\
\hline $\begin{array}{l}\text { Back and neck sprains, strains, non- } \\
\text { specific pain, or neurologic spine pain }\end{array}$ & $\$ 7,989$ & $\$ 10,966$ & $\$ 9,170$ & $\$ 11,247$ & $9 \%$ & $29 \%$ \\
\hline Other (non-back) sprains and strains & $\$ 4,219$ & $\$ 5,074$ & $\$ 4,343$ & $\$ 5,044$ & $5 \%$ & $24 \%$ \\
\hline Inflammations & $\$ 10,190$ & $\$ 13,017$ & $\$ 11,163$ & $\$ 13,325$ & $12 \%$ & $39 \%$ \\
\hline $\begin{array}{l}\text { Upper extremity neurologic (carpal } \\
\text { tunnel) }\end{array}$ & $\$ 8,795$ & $\$ 10,840$ & $\$ 11,934$ & $\$ 13,920$ & $15 \%$ & $59 \%$ \\
\hline Other injuries & $\$ 6,867$ & $\$ 9,058$ & $\$ 4,742$ & $\$ 5,699$ & $5 \%$ & $21 \%$ \\
\hline
\end{tabular}


Table 11. Coefficient Estimates from OLS and Quantile Regressions for Incurred and Developed Medical Costs at 36 Months of Maturity, Injury Years 2007-2010, All Claims, by Injury Group

\begin{tabular}{|c|c|c|c|c|c|c|c|c|}
\hline \multirow[b]{2}{*}{ Injury Group } & \multicolumn{4}{|c|}{$\begin{array}{r}\text { Incurred Medical Costs } \\
\text { Quantile Regression }\end{array}$} & \multicolumn{4}{|c|}{$\begin{array}{r}\text { Developed Medical Costs } \\
\text { Quantile Regression }\end{array}$} \\
\hline & OLS & $\begin{array}{c}90^{\text {th }} \\
\text { Percentile }\end{array}$ & $\begin{array}{c}95^{\text {th }} \\
\text { Percentile }\end{array}$ & $\begin{array}{c}9^{\text {th }} \\
\text { Percentile }\end{array}$ & OLS & $\begin{array}{c}90^{\text {th }} \\
\text { Percentile } \\
\end{array}$ & $\begin{array}{c}95^{\text {th }} \\
\text { Percentile }\end{array}$ & $\begin{array}{c}99^{\text {th }} \\
\text { Percentile }\end{array}$ \\
\hline Fractures & -8.8 & -9.8 & -7.3 & $-12.6^{*}$ & -8.0 & -8.1 & -3.8 & -7.1 \\
\hline $\begin{array}{l}\text { Back and neck sprains, strains, and } \\
\text { non-specific pain, or neurologic spine } \\
\text { pain }\end{array}$ & 10.6 & 23.8 & 15.3 & 4.9 & 13.1 & $32.6^{*}$ & 23.5 & 12.0 \\
\hline Lacerations and contusions & -8.8 & $-15.7^{\star *}$ & -10.6 & -5.3 & -8.8 & $-15.7^{* *}$ & -10.3 & -2.8 \\
\hline Other sprains and strains & -1.4 & 9.4 & 10.4 & 6.7 & -0.5 & 12.6 & 15.8 & 14.8 \\
\hline Inflammations & -3.9 & -4.7 & -3.1 & -0.9 & -2.2 & 1.7 & 4.8 & 4.9 \\
\hline $\begin{array}{l}\text { Upper extremity neurologic (carpal } \\
\text { tunnel) }\end{array}$ & -7.6 & -2.6 & -0.1 & -3.4 & -4.4 & 4.0 & 5.7 & 1.3 \\
\hline Other injuries & -2.1 & -3.7 & -5.1 & -7.5 & -1.3 & -1.0 & -1.1 & -2.6 \\
\hline
\end{tabular}

Notes: Estimates are from quantile regressions relative to the base category of states with employer choice of provider or employer control of panel, with very restricted options for workers to change provider. Full set of estimates is available from authors upon request. Standard errors are estimated allowing for intra-cluster correlation as in Parente and Santos Silva (2013), using qreg2 estimation in Stata with statelevel clustering (Machado, Parente, and Santos Silva, 2013). ${ }^{* \star *}$ statistically significant at $1 \%$ level, ${ }^{* \star}$ statistically significant at $5 \%$ level, * statistically significant at $10 \%$ level.

Table 12 Coefficient Estimates from OLS and Quantile Regressions for Incurred and Developed Indemnity Costs at 36 Months of Maturity, Injury Years 2007-2010, All Claims, by Injury Group

\begin{tabular}{|c|c|c|c|c|c|c|c|c|}
\hline \multirow[b]{2}{*}{ Injury Group } & \multicolumn{4}{|c|}{$\begin{array}{r}\text { Incurred Indemnity Costs } \\
\text { Quantile Regression }\end{array}$} & \multicolumn{4}{|c|}{$\begin{array}{r}\text { Developed Indemnity Costs } \\
\text { Quantile Regression }\end{array}$} \\
\hline & OLS & $\begin{array}{c}90^{\text {th }} \\
\text { Percentile }\end{array}$ & $\begin{array}{c}95^{\text {th }} \\
\text { Percentile }\end{array}$ & $\begin{array}{c}9^{\text {th }} \\
\text { Percentile }\end{array}$ & OLS & $\begin{array}{c}90^{\text {th }} \\
\text { Percentile }\end{array}$ & $\begin{array}{c}95^{\text {th }} \\
\text { Percentile }\end{array}$ & $\begin{array}{c}9^{\text {th }} \\
\text { Percentile }\end{array}$ \\
\hline Fractures & 11.3 & -20.5 & -13.2 & 1.0 & 12.7 & -16.2 & -5.3 & 14.8 \\
\hline $\begin{array}{l}\text { Back and neck sprains, strains, and } \\
\text { non-specific pain, or neurologic spine } \\
\text { pain }\end{array}$ & 43.2 & 4.3 & 13.0 & 15.4 & 46.1 & 16.6 & 29.4 & $31.1^{* *}$ \\
\hline Lacerations and contusions & 5.7 & 17.3 & -2.4 & -24.6 & 5.9 & 17.6 & -1.7 & -20.4 \\
\hline Other sprains and strains & 29.8 & 9.3 & 0.3 & 10.1 & 30.9 & 13.9 & 6.9 & 24.7 \\
\hline Inflammations & 2.5 & -13.5 & -2.6 & 6.0 & 5.2 & -4.0 & 9.1 & 20.2 \\
\hline $\begin{array}{l}\text { Upper extremity neurologic (carpal } \\
\text { tunnel) }\end{array}$ & -24.9 & -23.0 & -8.7 & 7.3 & -20.4 & -9.7 & 8.8 & 30.1 \\
\hline Other injuries & 11.8 & -5.2 & -14.1 & -0.9 & 12.9 & -0.8 & -7.0 & 11.9 \\
\hline
\end{tabular}

Notes: Estimates are from quantile regressions relative to the base category of states with employer choice of provider or employer control of panel, with very restricted options for workers to change provider. Full set of estimates is available from authors upon request. Standard errors are estimated allowing for intra-cluster correlation as in Parente and Santos Silva (2013), using qreg2 estimation in Stata with statelevel clustering (Machado, Parente, and Santos Silva, 2013). ${ }^{* * *}$ statistically significant at $1 \%$ level, ${ }^{* *}$ statistically significant at $5 \%$ level, * statistically significant at $10 \%$ level. 


\section{Appendix A (on-line): Reconciling Results with Shraim et al. (2015)}

This technical appendix discusses how the findings in our study compare with estimates from a recent analysis by Shraim et al. (2015) and whether the findings can be reconciled. Shraim et al. examined the relationship between workers' compensation provider choice policies and medical costs and duration of temporary disability for workers with low back pain. They found lower medical costs for low back pain cases in states where employers have more control over the initial provider choice, which contrasts with our findings. They also found higher medical costs in states that limit subsequent provider changes relative to states that allow a one-time provider change, but no difference in medical payments in states that do not allow a change in the treating provider and those that do not limit provider change; these latter results are not directly comparable to our results. In this appendix, we first highlight the most important differences in the empirical analysis in the two studies, and we then examine the differences in results and how to interpret the evidence from the two studies on the relationship between provider choice policies and workers' compensation costs.

\section{Differences between the two studies}

There are many differences in the empirical analysis in the two studies. We discuss these and their potential implications for interpretation of the results in turn.

\section{Incomplete policy controls}

To identify the effects of provider choice policies, it is important to adequately control for other important features of the workers' compensation system that can affect costs. Because of this, both studies use multiple controls for other workers' compensation policies designed to capture differences in claim costs. However, while some of these controls are common to both studies, some potentially important controls were not included in the Shraim et al. study.

- Shraim et al.'s analysis did not account for differences across states in fee schedule rates, but instead only controlled for whether states have a fee schedule. Their dichotomous classification ignores the fact that states with fee schedules apply quite different fee schedule rates, and these differences contribute to variation in medical payments per claim (Fomenko and Liu, 2012; Fomenko and Yang, 2015).

- Shraim et al. did not account for whether the state mandates the use of treatment guidelines or utilization review, even though these may be associated with lower medical and indemnity costs (Elam, et al., 1997).

- Shraim et al. did not control for whether the state was a wage loss state. This control is potentially important since the duration of temporary disability (one of the measures in their analysis) tends to be longer in wage-loss states, where workers with permanently disabling injuries may continue to receive temporary benefits, while workers in an impairment system may be shifted to permanent disability benefits. ${ }^{1}$

- The two studies use different controls for the replacement rate. Our study controls for individuallevel replacement rates for each worker, while Shraim et al. controlled only for the statutory replacement rate relevant for a state. The individual-level measure should be more predictive of individual behavior because it captures not only the variation in statutory replacement rates across states but also the difference in maximum and minimum weekly temporary disability benefits, which vary across workers depending on their preinjury wages.

We have already noted in the main text that the richer policy controls we use are significant determinants of medical or indemnity costs. If this policy variation is also correlated with provider choice policies, then excluding measures of this policy variation could lead to biased estimates of the relation of

\footnotetext{
${ }^{1}$ For more details, see Barth and Niss (1999).
} 
costs to provider choice policies. Later in this appendix, we show estimates suggesting that the Shraim et al. results are sensitive to excluding the controls we include and are biased toward finding higher costs in states where policies give workers more control over the choice of provider.

\section{Endogenous controls}

On the other hand, Shraim et al. include some regression controls that may be endogenous and capture, in part, the effects of provider choice policies. One such control is attorney involvement in a claim. In Technical Appendix C of Neumark and Savych (2017), we show that the results are a bit sensitive to whether the specification includes controls for attorney involvement. But we also argue that including attorney involvement as a control may lead to biased estimates of the effects of provider choice policies. Attorneys are less likely to get involved in cases in states where policies give workers control of provider choice, because when the worker has greater control of the choice of provider there is less reason for the worker to hire an attorney, which is also reflected in a lower likelihood that the defense does so. This means that attorney involvement may be more of an outcome of provider choice policy than something we want to account for in the model. In this case, the more meaningful comparison to infer whether policies giving workers more control of the choice of provider affects indemnity costs is the one that does not condition on defense attorney involvement but rather treats this higher involvement in employer control states as part of what the policy difference entails.

A similar concern applies to the controls that Shraim et al. include for whether workers had lumbar surgery or an early magnetic resonance imaging (MRI), and whether workers received an early opioid prescription. These variables may be informative about injury severity, but they may be potentially problematic because they can reflect outcomes of medical decisions that are made after an injury and may be driven by who controls the choice of provider. The concern, again, is that these measures capture the outcomes of provider choice policies that are more appropriately thought of as effects of these policies. In our analysis, we excluded controls for nature of medical treatment, although we showed in Neumark and Savych (2017) that the results are not sensitive. However, Shraim et al. include more, and different, controls for medical treatment, and we believe that models for estimating cost differences associated with provider choice policies should not control for differences in medical treatment. As shown below, excluding these endogenous controls appears to weaken the evidence that medical costs are higher in states where policies give workers more control of the choice of provider.

\section{Differences in definition of provider choice policies}

The two studies also differ in how they classify states in terms of provider choice policies. We compare two groups of states: (1) states with employer choice of provider or employer control of panel, with very restricted options for workers to change provider, versus (2) states with worker choice or where workers have considerable ability to change provider. Shraim et al. (2015) take a different approach and present comparisons for two separate dimensions of provider choice: (1) ability to choose the initial provider (employers or workers), and (2) ability to change provider (whether workers cannot change provider, whether they are only able to change once, and whether they can change providers without limits). These differences in definitions mean that we cannot compare the results from the two studies directly, since the different ways of examining policies do not map into each other. These differences in the definition of the policies are most acute when we compare states where workers choose from a network of providers. While those states are excluded from our analysis, they are included in the analysis by Shraim et al. as states where initial choice is either limited (Connecticut) or not limited (Kentucky, Minnesota, and Texas). ${ }^{2}$ Given that — as we argue in the main report—it is unclear how to characterize control of provider

\footnotetext{
${ }^{2}$ Also note that two states in Shraim et al.'s analysis changed provider choice policies, but these changes are not reflected in the provider choice policy variables that the authors used as controls. Effective January 1, 2005, California Senate Bill 899 allows employers to establish medical treatment networks, and workers can select providers from the network. All future provider changes and referrals had do occur within that same network. Prior to that, employers had the right to select the initial provider unless the employee had pre-designated a provider; but after 30 days, the worker
} 
choice in network states, we think that analysis excluding these states is more informative (although we are not arguing that it is unimportant to understand how restricting provider choice to a network affects costs).

Although the approach in Shraim et al. (2015) potentially provides additional information about the effects of different dimensions of provider choice policies, it also raises a concern about potential interactions between who controls the initial provider choice and the ability to change providers. Does the effect of ability to change providers differ based on who controls the initial choice of providers? This information may be useful for better understanding any differences in the results between the two studies. But estimates with the full set of interactive effects may not be that informative since some of the interactive effects may be identified from a small number of states. ${ }^{3}$ Finally, as noted above, Shraim et al. found a result with regard to the effect on medical costs of ability to change provider that is difficult to explain - with the "intermediate" regime of allowing a one-time provider change exhibiting the lowest medical costs.

\section{Different states}

The two studies examine different numbers of states. Our study includes 25 states in the two general policy groups outlined above. Shraim et al. (2015) include data from all 50 states plus the District of Columbia. This difference can obviously threaten the validity of any comparisons, although since Shraim et al. include states that cannot be easily classified (if at all) as states with predominantly employer control versus predominantly worker control of provider choice, their inclusion of more states does not necessarily make their estimates more valid. In general, however, information from more states is potentially valuable.

\section{Different claims}

Another concern is the selective nature of claims included in different states-differences that may be correlated with claim costs. Shraim et al. use data from a single private insurer that represent about 10 percent of the U.S. private workers' compensation market. However, the sample representation varies substantially across states. In some states, the sample may capture only a small percentage of claims and may not be representative of the overall market. This may lead to bias in the estimates for provider choice policies if the claims captured in the sample are different from other claims in the market. For instance, in the states with large state funds, the analysis sample would include primarily claims from self-insured employers, which may skew results for a given state. ${ }^{4}$

\section{Differences in definitions of dependent variables}

The two studies also use different definitions of the main dependent variables. Our study uses incurred medical and indemnity costs as well as projected developed medical and indemnity costs measured at 36 months' maturity. Shraim et al. examined medical payments that were accumulated only through the first year after an injury. These differences limit comparability of the results reported in the two studies, and we would expect that costs of longer maturity are more relevant to assessing evidence on ultimate costs. (And we show, in Neumark and Savych (2017), that our results are robust to using 60

had the right to change to a medical provider of his or her own choice. In Texas, effective January 2006, if the insurer has contracted with a medical network, the injured employee can initially choose a treating provider from the network list. Prior to those reforms, workers chose providers from the Commission's Approved Doctor List (ADL).

${ }^{3}$ We discuss this in more detail in Technical Appendix B of Neumark and Savych (2017), where we emphasize the importance of a parsimonious specification of provider choice policies.

${ }^{4}$ Consider, for example, the distribution of claims in Ohio and Washington reported in Shraim et al. (2015). These two states represent 0.58 and 0.38 percent of their sample (Appendix 3), while reflecting 3.7 and 2.2 percent of the U.S. population. Since these two states have an exclusive state fund for workers' compensation insurance, Shraim et al.'s sample for these two states includes mainly self-insured employers, and it is possible that self-insured employers have different approaches for dealing with injuries and return to work after an injury, leading to different costs than the rest of the market. 
months' maturity data.)

\section{Comparing differences in estimates}

We have listed many differences between the two studies and discussed some reasons why we think our study gives more reliable estimates of the effects of provider choice policies. However, we can go further by using our data source to match as closely as possible the data used by Shraim et al., and then use these modified data to explore the effects of many of the issues discussed above on the estimated medical and indemnity cost differences between states based on provider choice policies. We cannot, however, fully assess the importance of some of the concerns outlined above since we do not have the data used by Shraim et al. for all states. This analysis focuses only on medical costs, where the central results of our study and those of Shraim et al. differ.

The results of our attempt to see if we get similar results to theirs using our data, and then to explore what might explain the differences between the studies, are reported in Table A.1. The first column of Table A. 1 shows results for the OLS specification ${ }^{5}$ for the sample of low back injuries in years 2008 2010 across 30 states. $^{6}$ This is our best replication of the Shraim et al. results. The sample definition follows their rules, including their focus only on lower back injuries, with the exception that our data set includes a large number of claims from a greater number of workers' compensation payors, although these claims reflect experience in a smaller number of states for which our data are available. The estimates in column 1 indicate higher average medical costs when workers are allowed to choose providers. Although the estimated differential of 8.9 percent is not statistically significant, it is in the same direction as the results in Shraim et al. (2015). However, our results for the ability to change provider do not replicate their results. We find lower average medical costs when workers are allowed to change the treating provider without limit, whereas they found the lowest medical costs when workers are allowed to change once. We have no explanation for this difference, and from here focus more on the estimated difference in costs associated with employer versus worker control of the choice of provider.

In column 2, therefore, we instead focus on the classification of provider choice policies that we use in our study. Using this classification, but otherwise mimicking Shraim et al.'s sample and specification, we find higher medical costs (by 8.9 percent) in states that allow workers to choose providers or to have considerable ability to change provider. Although this estimated difference is not statistically significant, it is qualitatively similar to the key result for medical costs and provider choice policies in Shraim et al. (2015).

Having more or less replicated their results, we explore the other issues raised above. In all cases, we find that in the other specifications we estimate, the evidence of higher costs in states where policies give workers more control of the choice of provider weakens, or even reverses, consistent with upward bias in Shraim et al.'s estimates of relative medical costs in states where policies give workers more control of the choice of provider. In columns 3 and 4, we compare how the estimates change when we add other workers' compensation policy variables that were not controlled for in Shraim et al. (2015). The estimates in column 3 , compared with the estimates in column 1, show no impact of the initial provider choice on average medical costs; the estimated differential changes from 8.9 percent to -1.6 percent. And similarly comparing columns 2 and 4 shows that with the additional policy controls, the evidence of higher medical costs where policy gives workers more control of the choice of provider weakens-from 8.9 percent higher to 4.7 percent higher. There is no clear evidence of higher costs when we use a more complete set of controls for other workers' compensation policies.

The next two specifications show that estimates for provider choice policies are also sensitive to including controls for attorney involvement and other medical treatment. As discussed above, we think of these measures as potential outcomes of the provider choice policies and, therefore, that we should not control for these in the regression analysis. We find that the evidence of higher costs under policies giving

\footnotetext{
${ }^{5}$ The coefficient point estimates are very similar when we used the multilevel mixed-effects linear regression employed by Shraim et al.

${ }^{6}$ Unlike the analysis in the main part of the report, the analysis here includes states where workers could choose providers from a network.
} 
workers control of the choice of provider weakens further when these endogenous controls are omitted; in particular, comparing columns 4 and 6, the estimated coefficient falls from 4.7 percent to 2.1 percent.

What can we conclude from this analysis? First, we emphasize that none of the average cost differences associated with our two-way classification of provider choice policies are statistically significant. Thus, using our data to look at the limited set of injuries Shraim et al. studied never provides statistical evidence consistent with their conclusion that medical costs are higher when workers have more control of the choice of provider. Moreover, the point estimates are different. For medical costs, our estimates point to small or essentially no cost differences, whereas Shraim et al. reported that greater ability of workers to choose providers results in higher medical costs. However, the data and states included in the two studies are different, which could account for the discrepancies in findings. On this score, it is not necessarily clear that one set of estimates is more convincing than the other. Second, however, some of the decisions made in their analysis - about using a more limited set of controls for other workers' compensation policies and including potentially endogenous controls - appear to lead to stronger evidence that medical costs are higher when workers have more control over the choice of provider. In contrast, following decisions about these issues as in our study, but using our data to study the lower back injuries on which Shraim et al. focus, we find point estimates more consistent with our conclusions - that there is no evidence that policies giving workers more control of the choice of provider are associated with higher medical costs, and they may be associated with lower medical costs.

There are some elements of differences between the two studies we cannot consider, however, such as differences from using all the states and the representativeness of the claims in their data. Thus, we cannot be certain what would happen if we could use Shraim et al.'s data but make the other changes in specification and sample that we highlight in this appendix. We suspect, however, that we would find weaker evidence that medical costs are higher when workers have more control of the choice of provider, and possibly no evidence of this or evidence in the opposite direction. This conjecture is partially supported by our analysis in Technical Appendix C of Neumark and Savych (2017), showing that representativeness of the states in our data relative to the nearly complete set of states in the NCCI data creates a bias in the direction of higher costs in states where policies give workers more control; that is, all else the same, a more representative set of states appears to yield evidence even less consistent with medical costs being higher in these states. Finally, the results in Shraim et al. (2015) only examine one type of claim. So even if we take their evidence as valid for these claims, their conclusions are not generalizable to other types of claims. 
Table A.1. Reconciling Estimates for Medical Costs with Estimates from Shraim et al. (2015)

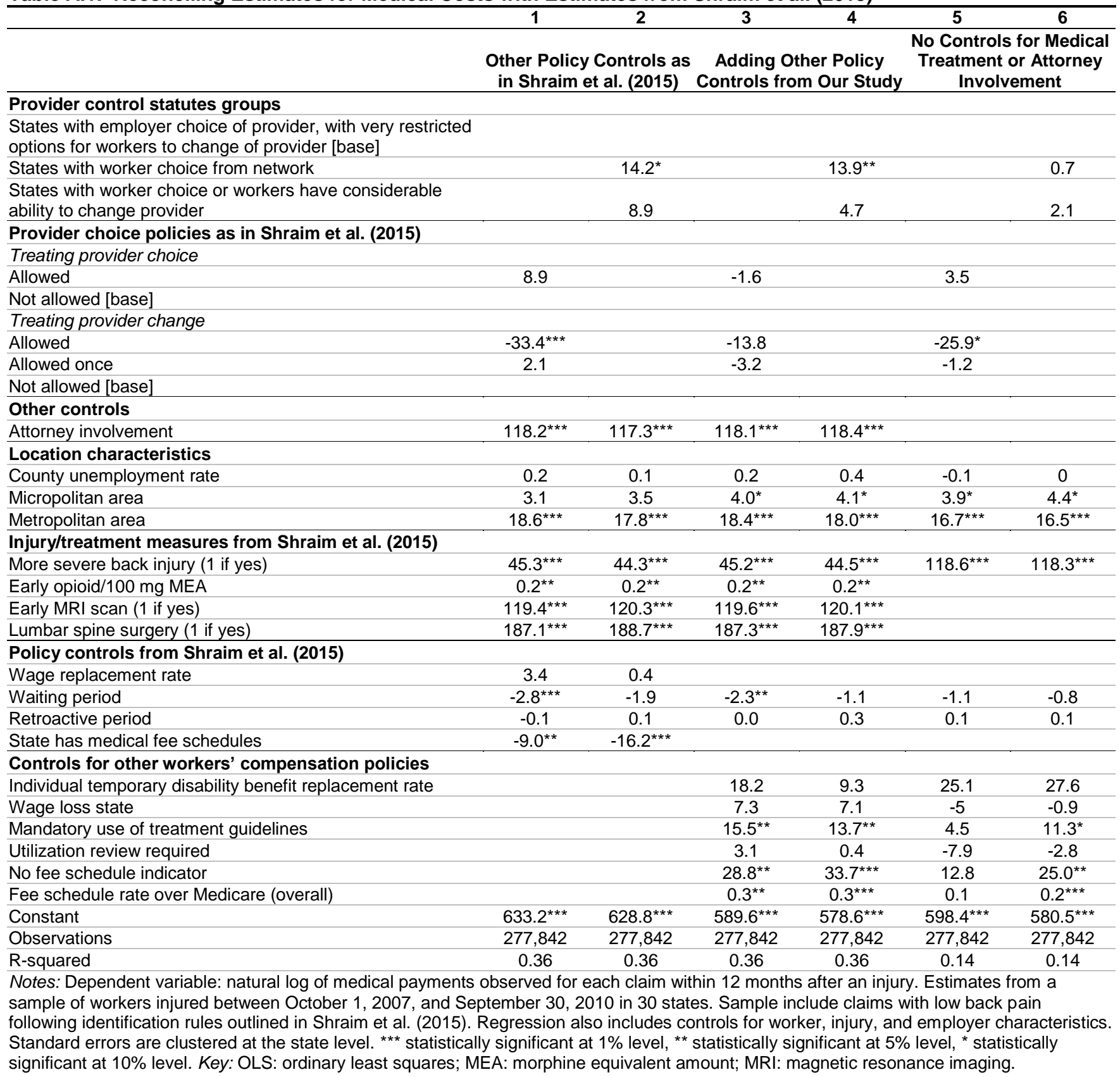

